\title{
EL DEBATE DE LO PÚBLICO Y LO PRIVADO EN SERVICIOS SOCIALES
}

\section{MANUEL ENRIQUE MEDINA TORNERO.}

Profesor de Servicios Sociales. E.U. de Trabajo Social. Universidad de Murcia.

\section{INTRODUCCIÓN}

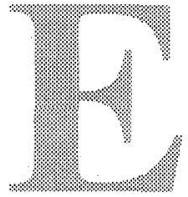

I debate sobre lo que debe ser una prestación realizada desde la Administración Pública o desde las entidades privadas, sean éstas de carácter lucrativo o no, no es nuevo, ni tampoco se va a acabar en los próximos años; somos de la opinión que acompañará durante mucho tiempo al todavía incompleto Sistema Público de Servicios Sociales. Pero lo que no podemos negar es que este tema siempre despierta un vivo interés, y estimo que cada vez se plantea con más virulencia, con más pasión que razón en los argumentos, tanto a favor como en contra. Se presentan opiniones sobre ideologías antisolidarias, sobre el mercantilismo como valor central de la vida social, como un proceso de recortes del bienestar social, como una permanente amenaza de privatización. Y todos estos argumentos olvidan en muchas ocasiones a los empleados públicos y a los usuarios, auténticos protagonistas de una obra de teatro en la que otros son los que reparten los papeles sin atenerse siquiera a un guión preestablecido, con una manifiesta falta de dirección, o, lo que es lo mismo, se critica la ausencia de eficiencia y no se pone en evidencia la poca inversión en formación o en transformación de las organizaciones necesitadas de profundos cambios que consigan desprenderse de culturas arcaicas, instaladas en el asistencialismo tan denostado y criticado por todos.

Algunos antecedentes de este tema nos indican que siempre ha estado vivo, Laparra (1989) nos planteaba un retrato auténtico de la privatización de los servicios sociales en Navarra; Cabrero y otros (1991) abordaban en una interesante obra colectiva los fenómenos de privatización y su relación con el bienestar social y en la misma línea el Institut de Treball Social i Serveis Socials (1991) convocaron unas jornadas de encuentro en torno al sugestivo título de lo público-privado y el bienestar social, en el que se dieron cita algunos de los pensadores con más interés sobre este tema. Desde una perspectiva más general, Manuel Jesús González (1994) ha abordado el tema mediante una pregunta ¿Adónde va el sector público? Del Estado de Bienestar al Bienestar con menos estado. La privatización de servicios sociales 
(Martín Santos, 1995), y, ya antes, Barinaga (1994) se preguntaba por una redefinición del Estado del Bienestar en el que se contemplaba la privatización. En este año algunas obras han puesto de relieve que el tema de la privatización puede ser un fantasma que aparece y desaparece como un efecto Guadiana (Mota, 1998); la influencia de las subvenciones para eliminar competencia siguiendo la política europea restrictiva (Ripoll, 1998), o el papel de las Administraciones en la dialéctica Estado-mercado (Subrá de Bieusses, El País, 6-XI-1998), entre otras publicaciones. Fuera de nuestras fronteras, y sin ánimo de ser exhaustivo, algunos apuntes nos pueden poner en antecedentes. El gran debate abierto en Francia en 1995 convocado por la revista Vie Sociale bajo la inquietante pregunta de L'Etat-providence, quel avenir?, o los trabajos de Donati (1996) que posteriormente insistiría (Donati, 1997) sobre la necesaria configuración moderna de los servicios de bienestar social entre los que no se olvida de los fenómenos privatizadores y contestado enseguida por Ranci (1996) y Puppo (1996) y acertadamente cerrado el debate, es un decir, por el maestro Ascoli (1996) y una de sus alumnas (Ota de Leonardis, 1996). En Inglaterra los trabajos clásicos de Kirk Mann (1991) o los siempre atrayentes de Peter Taylor-Goory (1991) nos acercan las posiciones inglesas que tanta tinta han hecho circular sobre un tema tan preocupante para los ingleses como los niveles de bienestar adquiridos; trabajos complementados por Cree (1996) y la visión de una americana en Londres como es Paula Kearns (1997) en torno a la privatización de los servicios personales, y las declaraciones del primer ministro Tony Blair sobre la reforma del bienestar social en el Reino Unido (El País, 17$\mathrm{V}$-1998). Y en nuestro país encontramos un debate abierto en los primeros días de diciembre sobre la creación de fundaciones sanitarias que gestionen los hospitales públicos, lo que ha puesto el tema de lo público y lo privado en el ojo del huracán, lo que, sin duda, viene a llenar de actualidad el tema que aquí vamos a abordar (véanse los artículos, a modo de ejemplo en el diario El País 1, 2, 3 y 4 de diciembre).

\section{EL ESTADO DE BIENESTAR Y EL MERCADO}

El Estado de bienestar se ha convertido en uno de los elementos centrales del debate económico, social y político de las sociedades desarrolladas, en especial de las europeas, en este final de siglo. De hecho, puede afirmarse que el sistema de protección social, tal como existe en la actualidad, atraviesa una crisis, cuyo origen puede resumirse en tres puntos esenciales, según algunos autores actuales (Buchanan, 1997; Espinosa de los Monteros, 1997): los cambios registrados en la estructura demográfica de las sociedades occidentales, los crecientes 
problemas financieros del Estado de bienestar, 'sus negativas consecuencias sobre la actividad económica y el empleo.

España es un caso paradigmático. El desarrollo del Estado de bienestar ha experimentado un importante impulso en los últimos quince años. Este país ha recorrido en poco más de diez años un camino que a otros países les ha costado décadas. La expansión de los llamados gastos sociales se ha producido, además, sin tener en cuenta si la economía española podía o no financiar en el largo plazo un sistema de protección social tan extenso y pretendidamente generoso.

El crecimiento del Estado de bienestar, tal y como está hoy concebido, es a largo plazo incontrolable. La mezcla de universalidad, gratuidad y carácter público de las prestaciones determina el crecimiento incontrolable del gasto, tanto por su propia estructura (a precios cero demanda infinita) como por ser objeto de competición entre los partidos políticos que concurren a las elecciones (Espinosa de los Monteros, 1997). En suma, el Estado de bienestar, en su versión actual, ha pasado de constituir una solución a convertirse en un problema. Las reformas orientadas al mercado que se produjeron en los países europeos a partir de los años ochenta no afectaron a los sistemas de protección social que emergen a finales de siglo como uno de los factores determinantes de la actual «euroesclerosis». El impacto de los costes del Estado de bienestar sobre la actividad económica y sobre la competitividad ha sido, y es, un factor determinante de la relativa decadencia económica del Viejo Continente, según la perspectiva de los sectores productivos privados, y, desde esta postura, para ellos es preciso constituir un nuevo modelo de protección social en Europa en el que la cobertura estatal se extienda sólo a quienes realmente la necesitan, que no genere desincentivos y que sea económicamente sostenible. De aquí que la reforma del Estado de bienestar deba enmarcarse en un proceso de reforma global de la economía, dirigida a reducir el papel del Estado en la vida económica y social y proponen para ello dos vías: primera, que el Estado libere a los ciudadanos de la obligación de consumir determinados bienes ofrecidos por el sector público y pagados mediante impuestos (sanidad, educación, pensiones, etc.), permitiéndoles cubrir su demanda de este tipo de bienes en el mercado; segunda, que el Estado garantice el acceso de todos los ciudadanos a un paquete de servicios públicos (donde público no es lo mismo que estatal), pero desmonopolice su prestación.

La primera alternativa supone, desde la perspectiva defendida por el Círculo de Empresarios en la X Conferencia Internacional dedicada a examinar el Estado del bienestar, desde la perspectiva del sector privado, la privatización del actual teórico estado del Bienestar Social y dar el paso hacia un Estado factible de bienestar; la segunda, más 
modesta, supone eliminar el papel monopolístico del Estado en la oferta de determinados servicios. Según estas posiciones, y en la actualidad, la inmensa mayoría de las tareas de bienestar social monopolizadas por los poderes públicos podrían ser desempeñadas por la sociedad civil, lo que no sólo sería más eficaz, sino que además contribuiría a fortalecer los cimientos morales sobre los que reposa una sociedad libre: la responsabilidad individual, la solidaridad natural y la cooperación voluntaria.

Sin embargo, en el caso de los Servicios Sociales, los ciudadanos han seguido y seguirán, aún durante bastante tiempo, demandando ayudas y asistencia, con una cultura asistencial anclada en sus demandas $y$, a veces, una cultura organizacional y profesional que como único recurso tenía, y en ocasiones sigue teniendo, la respuesta asistencial.

Aunque hemos de ser conscientes que esta situación está entrando en conflicto últimamente. La creciente preocupación por el crecimiento cada vez mayor de la Administración Pública y, consiguientemente, del gasto público y, más concretamente, del gasto social, sin una relación directa con su nivel de eficacia -en tiempos en los que la racionalización y optimización de los recursos son un elemento clave en cualquier tipo de gestión- ha generado este conflicto que, a su vez, ha hecho que países de un alto nivel de desarrollo (Estados Unidos, por ejemplo) aborden este tema como prioritario en sus debates políticos, es decir, como un elemento que puede contribuir notablemente a mejorar la calidad de vida de sus ciudadanos, incluyendo de forma paralela un amplio capítulo de recorte en sus gastos sociales que ha puesto en peligro la protección de diversos colectivos sociales. Sin embargo, en este punto conviene hacer una distinción que en ocasiones puede producir confusión, al ser traducido su significado desde Estados Unidos, y es el término welfare state (considerados como los servicios de carácter universal como la Seguridad Social) del welfare services (los servicios asistenciales que sí han sufrido un considerable recorte en Estados Unidos) tanto con políticas demócratas como republicanas, dependiendo de la bonanza económica (Navarro, 1998).

\subsection{El desmantelamiento del Estado de bienestar: algunas consecuen- cias sobre la equidad.}

En su "best-seller", The State We're in, Will Hutton (1995) ha destacado el crecimiento mundial de las últimas décadas convencido de que los mercados son la solución a las dificultades económicas.

Durante los años posteriores a la II Guerra Mundial se produjo una notable intervención del Estado en la economía de muchos países industrializados. La propiedad estatal de los componentes clave de los 
medios de producción, incluyendo los principales servicios públicos (agua, gas, ferrocarriles, electricidad, barcos y otros) estaba a la orden del día. Sin embargo, durante los últimos veinte años, la privatización se ha extendido desde las economías industrializadas hasta las naciones más pobres y, en la actualidad, a muchos países del antiguo bloque comunista. La pérdida de fe en la intervención y regulación del Estado ha sido reemplazada por una nueva confianza en la propiedad privada y en los precios flexibles de los mercados liberalizados. Como indica Hutton (1995, pág. 16): «Se ha puesto en marcha el gran concurso ideológico del siglo XX. Los mercados libres capitalistas han vencido; la planificación del Estado y el comunismo, de los que se deriva el capitalismo social, han sido derrotados».

Vemos la existencia de un amplio movimiento intelectual y de unas políticas que se dicen tendentes a revitalizar la iniciativa privada y el espíritu empresarial; aunque, están (y esto es, para nosotros, muy importante) las actitudes y expectativas ciudadanas con respecto al comportamiento estatal y a los papeles que lo público y lo privado asumen, como ya señalara a principios de esta década el profesor Cabrero (1991) en el cumplimiento de aquellas.

La dinámica de cambio social ha ido modificando y difuminando las fronteras entre lo que se denomina sector público y privado. Las continuas interconexiones parecen obligar a abrir un debate de reflexión sobre aquello que define uno y otro sector y la naturaleza de las relaciones que se van introduciendo.

Por otra parte, así como hace unos años el peso de este proceso de reflexión y aprendizaje se situaba en la necesaria democratización de las estructuras políticas representativas, y en el refuerzo del tejido asociativo, hoy, después de una cierta consolidación democrática, el acento empieza a ponerse en la capacidad de gestión de instituciones y asociaciones. Mejorar la gestión puede significar mejorar la calidad de las prestaciones y profesionalizar definitivamente el sector de servicios sociales que ha ido creándose y extendiéndose. Este debate quedó solapado durante años por la necesaria consolidación del Sistema Público de Servicios Sociales. Todos estábamos de acuerdo en que era preciso que las instituciones públicas tomaran consciencia de que era urgente el desarrollo de políticas de servicios sociales que abandonaran actitudes asistencialistas, para, en un segundo orden de prioridad establecer mecanismos conducentes a la entrada de las entidades privadas, del tipo que fuera, en el Sistema.

Pero, al mismo tiempo, hemos de ser conscientes de que durante los últimos años tanto el sector público como el sector privado han experimentado importantes transformaciones: algunas de ellas derivadas de los mismos procesos que se han producido en un marco más 
amplio que el Estado y, por tanto, comunes a lo que está pasando en otros países, y ha ocurrido en otras áreas institucionales, y todo ello, debido, entre otros argumentos, a:

- El fuerte crecimiento de los servicios personales.

- Estas transformaciones se han producido en el proceso de adaptación del país al modelo del Estado del Bienestar Social.

- Por un lado, el sector privado ha visto cómo se estructuraba, juntamente a otras realidades ya existentes, el hecho asociativo.

- Además, con el gran incremento de la gestión indirecta de los Servicios Personales se han comenzado nuevas dinámicas que obligan a los diferentes agentes a resituar sus espacios y dibujar un nuevo sistema de relaciones y de poderes que más adelante analizaremos.

Utilizando unos parámetros de finalidad y entorno, podríamos, de acuerdo con las propuestas de Intress (1991), definir diversas situaciones entre público y privado.

Desde el punto de vista de la finalidad, podemos identificar:

- El mundo de lo privado con lucro, con una finalidad definida de obtener beneficios como resultado de la gestión y con la posibilidad de excluir clientes.

- El mundo de lo privado no lucrativo, donde el beneficio es una condición de supervivencia pero no una finalidad. Sus criterios de gestión son más amplios que en lo privado lucrativo e incluyen finalidades de bien social, pero mantiene la posibilidad de excluir clientes.

- El mundo de lo público, con unos criterios de gestión que persiguen el interés común y sin la posibilidad de excluir clientes a voluntad, matizando este elemento en la definición de prioridades políticas.

Desde la perspectiva del entorno tenemos:

- Un entorno de mercado, definido por la posibilidad de escoger por parte de los clientes y por la competencia entre los productores, y

- un entorno de no mercado, donde no existe la competencia ni la posibilidad de escoger el producto por parte del cliente.

\subsection{El mercado en la provisión de servicios sociales}

A lo largo de la década de los 80 se ha alcanzado en Europa un amplio consenso acerca de la idoneidad y la necesidad de combinar adecuadamente Estado y mercado en la provisión de un número creciente de bienes y servicios públicos, y, muy especialmente, en aquellos más representativos del Estado del Bienestar: los servicios personales (sanidad, servicios sociales, educación). 
Desde el recurso directo al mercado (contratación externa) a la creación de un contexto que estimule la competencia entre las organizaciones públicas (y privadas) responsables de la prestación de servicios públicos; la incorporación del mercado responde siempre a una voluntad política de introducir en la actuación de las Administraciones públicas una mayor preocupación por la eficiencia en la utilización de los recursos y por el control del gasto público. En ocasiones, también se persigue una mayor eficacia en la satisfacción de las necesidades de los ciudadanos, considerados ahora como clientes de la Administración.

Como consecuencia, se sitúan en un primer plano valores y comportamientos que tradicionalmente habían tenido una importancia secundaria en la actuación de las Administraciones públicas, mucho más preocupadas por los aspectos de legalidad, regularidad procedimental, equidad e igualdad de oportunidades.

Teniendo como referente las diferentes experiencias de modernización emprendidas en Europa, en la actualidad, el debate teórico y práctico se plantea en términos de cuál debe ser la proporción entre Estado y mercado en la provisión de servicios públicos y de cómo articular la relación entre los sectores público y privado en dicha actividad (Mendoza, 1991).

\section{III. ¿UNA NUEVA IMAGEN DE LOS SERVICIOS PÚBLICOS EN EUROPA?}

Tanto los que defienden como los que abominan la ideología del servicio público, creen que se está produciendo al final del milenio un cambio radical. Este es casi el único pensamiento en común entre quienes creen que el servicio público ha muerto y los que piensan que nada hay en el horizonte que permita sostener semejante diagnóstico. Pero el servicio público es el corazón del Estado, de modo que una variación de sus reglas toca el centro de la organización de la convivencia. Se justifica, por ello, la alarma, cada vez que se mueve la tierra debajo de la clave de bóveda de los modernos sistemas políticos europeos (Mescheriakoff, 1991).

Lo cierto es que hay un fuerte movimiento que preconiza aires de cambio. Las causas del cambio son muchas. Las más generales, explicadas en el ámbito económico, se relacionan con los fenómenos de la globalización o la mundialización de la economía, que exige que las empresas se preparen en un nuevo ambiente de competitividad. La apelación a la iniciativa privada, que los desarrollos indicados hacen inevitable, ha requerido la fijación de un marco regulador distinto, 
que pivota sobre tres ideas fundamentales: primera, la privatización de sectores económicos que estaban integrados en el sector público o controlados y gestionados por administraciones y establecimientos públicos; segunda, la liberalización, que opera complementariamente, aunque con independencia de las medidas de privatización, y procura una reducción de las intervenciones públicas en los sectores económicos fundamentales para el desarrollo de la competitividad y el empleo; y tercera, la aplicación a las relaciones entre empresas del principio de igualdad y de las reglas del mercado, entre las cuales son fundamentales los principios de libre competencia, que tanto la Comisión Europea como las autoridades nacionales se ocupan de salvaguardar (Muñoz, 1998).

Como reconoce el documento de trabajo del Parlamento Europeo sobre empresas públicas y servicios públicos económicos en la Unión Europea (Entreprises publiques et services publics économiques dans l'Union Européenne, 1996), el lugar de las empresas públicas y su papel de servicio público fueron puestos en cuestión en los años ochenta. Existía al principio un movimiento de hostilidad hacia las empresas públicas en tanto que tales, procedente de la voluntad de reducir el papel de los poderes públicos en la economía y también en virtud de un principio liberal que postulaba la disminución general de dichas posiciones en nombre de la eficacia económica.

Los ideólogos del nuevo Estado mínimo imaginan una retirada progresiva de la acción del Estado sobre la sociedad, que empieza por una significativa transferencia hacia la empresa privada de la iniciativa y el control de los sectores económicos fundamentales, para continuar con la reducción drástica de los servicios de carácter social (Muñoz, 1998). La competencia y el mercado serían el lugar donde la sociedad autoabastecería sus necesidades de cualquier orden. En el contexto de una economía globalizada, el mundo entero quedaría convertido en un enorme mercado, en el que tendría difícil cabida cualquiera de los servicios públicos tradicionales, organizados, además, en ámbitos territoriales ridículamente pequeños, comparados con las magnitudes universales de los flujos económicos. A la postre, el adelgazamiento radical del Estado es una alternativa de organización de las sociedades que tiende a liquidar, incluso, alguno de los elementos básicos sobre los que el Estado se fundó.

Pero, suponiendo que la liberalización y la privatización alcancen los extremos máximos que los ideólogos del Estado mínimo pretenden, sería injustificada la conclusión de que la reforma incluye como precio la muerte de los servicios públicos. Esta valoración sobre la posición de los servicios públicos en el futuro está apoyada en un análisis erróneo de los cambios que se están produciendo, y en una des- 
mesurada exageración que Muñoz (1998), apoyado en su dilata experiencia como analista de servicios públicos, disecciona con precisión de cirujano, acotándolo en dos razonamientos.

En primer lugar, porque los únicos servicios públicos atacados por las reglas del mercado son los de carácter económico. No los servicios que requieren el empleo de autoridad, y remarca con énfasis: tampoco los servicios de carácter social. En segundo lugar, y sobre todo, porque quienes auguran la destrucción del servicio público no suelen preocuparse de establecer a qué servicio público se refieren. Es sabido que esta noción es de las más lábiles y cambiantes del Derecho público moderno. Existen servicios públicos monopolizados y otros que no lo están, servicios públicos atribuidos a la titularidad de la Administración y otros calificados como tales y gestionados directamente por privados. Los servicios públicos funcionan conforme a un régimen de Derecho público o de Derecho privado, según los casos.

La cuestión a resolver, por consiguiente, es si los procesos de privatización y liberalización que están afectando tan fuertemente a las economías europeas al final del milenio exigen un cambio radical de óptica para que sean las empresas privadas las que cumplan las misiones de servicio público que requiere el interés general y son imprescindibles para la convivencia. $\mathrm{O}$, por el contrario, si, pese a todos estos cambios, la tradición europea del servicio público como obligación del Estado, como actividad tutelada y dirigida por el Estado, se mantiene (Muñoz, 1998).

Abundan cada vez más en los últimos años las reivindicaciones de la idea europea de servicio público, formuladas algunas de ellas con la misma exageración con la que se pronostica su muerte.

Francia ha construido como ningún otro Estado europeo la ideología y la técnica del servicio público. La idea de servicio público que el ordenamiento comunitario pone en crisis se suele identificar como la «concepción francesa del servicio público». Y la calificación está hecha con toda justicia. Pero se comprende que sea también en Francia donde se están produciendo las defensas más ardorosas de la noción tradicional. Una resolución de la Asamblea Nacional, presentada por la delegación francesa en la Unión Europea, afirma de manera rotunda que "los principios del servicio público tocan a la organización misma de la sociedad francesa y no son negociables, en particular con las instancias comunitarias". Y añade que "sólo el pueblo francés está legítimamente habilitado para definir estos principios y sacar las consecuencias en términos de organización" (Kovar, 1996, pág. 205).

Kovar (1996) ha hecho un detenido análisis de la defensa francesa del servicio público tradicional. La justifica "en la importancia otorgada por el Derecho administrativo a la institución del servicio públi- 
co, pero igualmente a una tradición de intervencionismo estatal más afirmada que en la mayor parte de los demás Estados de la Unión Europea" (Kovar, 1996, pág. 215).

La verdad es que la Comunidad se ha rendido inmediatamente en este enfrentamiento. Su desconsideración inicial por el servicio público, cuando empezó a exigir la aplicación estricta de las reglas de competencia contenidas en los artículos 85 y siguientes del Tratado CEE, ha cedido ante algunas evidencias que se han acumulado ante los ojos de los responsables de los organismos comunitarios que, en opinión de Muñoz (1998) y a la vista de los nuevos documentos sobre Política de la Competencia en la Comunidad, se pueden concretar en tres aspectos:

El primero es la fuerza de las convicciones ideológicas de la mayor parte de los Estados miembros de la Comunidad. El Estado prestador de servicios, ocupado también de la solidaridad y el bienestar de los ciudadanos, es un activo cultural al que no se piensa renunciar.

El segundo es que la propia Comunidad ha tenido que llegar inmediatamente a la conclusión de que las regulaciones de los Tratados no son incompatibles con los servicios públicos. Postulan, en la mayor parte de los casos, adecuar a un entorno concurrencial las reglas de organización y funcionamiento de los servicios públicos, pero, en modo alguno, reclaman su desaparición.

Y el tercero, que la presión de los defensores del servicio público no sólo no se ha conformado con el cambio de actitudes de los agentes y autoridades europeos, sino que, además, ha propiciado la elaboración de un proyecto de Carta de los servicios públicos, fechada el 14 de febrero de 1994. Aunque referida principalmente a los servicios de carácter industrial y comercial, se apoya en que la idea de mercado no es indiferente a los objetivos de solidaridad, cohesión o equidad. También en que es necesario corregir el libre funcionamiento del mercado para que sean atendidos algunos intereses generales que resulta imposible satisfacer con el exclusivo juego de las fuerzas del mercado (Europe Concurrence et Service Public, 1995).

"La solidaridad y la igualdad de trato en el contexto de una economía de mercado abierta y dinámica, constituyen objetivos fundamentales de la Comunidad Europea. Los servicios de interés general contribuyen a la consecución de estos objetivos. Los europeos esperan servicios de calidad a precios asequibles. Para muchos de ellos, estos servicios de interés general suponen auténticos derechos sociales y participan en gran medida en la cohesión económica y social. Por ello, los servicios de interés general están en la base del modelo europeo de sociedad ..." (Los servicios de interés general en Europa. D.O.C.E., 26-IX-1996). 
Resulta, por tanto, que Europa no abomina del servicio público, sino que simplemente quiere ajustarlo a un entorno de competencia. Todo ello será un nuevo reto para el servicio público, pero no supondrá su liquidación. Ni siquiera será un reto nuevo.

\subsection{La naturaleza y los principios de lo privado}

Según lo visto hasta ahora, los presupuestos ideológicos de la actuación pública persiguen un fin determinado que consiste básicamente en el logro de la cohesión social. Este fin no se puede predicar del sector privado ya que su naturaleza se basa en el logro del beneficio particular frente a terceros, por mucho que el Estado del Bienestar haya suavizado el descarnamiento del fin de las empresas capitalistas. En definitiva, el sector privado antepone el interés particular, sin ningún tipo de intermediarios, sobre el interés general, aun entendiendo éste de una forma poco altruista, como ya se ha expuesto.

La regla fundamental por la que se rige la actuación privada es el beneficio. Este actúa como fin y como límite, ya que traspasar la línea en la que una actividad no es rentable, lo cual es debido a muchos factores y no todos ellos de carácter económico, puede suponer el cese de la actividad. También es cierto que el beneficio en nuestro Estado tiene una gran carga socializante al entender que la actividad privada transciende su ámbito al implicar derechos individuales y colectivos. En una visión menos teórica: la sociedad asume la expulsión o fracaso en el mercado de las empresas privadas mediante la socialización de pérdidas, bien a través de subvenciones y ayudas, bien mediante el sostenimiento de la mano de obra inactiva, Por ello, la exigencia de la eficiencia en el sector público es también una exigencia del mismo principio en el sector privado.

Siguiendo la línea argumental del apartado anterior, la utilización de los mismos procedimientos de gestión en una actividad determinada en el sector público y en una empresa privada no significa que los fines a conseguir sean los mismos, ya que el beneficio en el ámbito de lo público es un factor más a considerar. En cualquier caso, en el ámbito de los servicios públicos, y más en los sociales, no se puede hablar del principio de beneficio aplicado a los mismos si no se le adjetiva de social. Lo mismo cabe decir de otros conceptos como el de eficacia, eficiencia, productividad o coste-beneficio que veremos más adelante. 


\section{DIÁlOGO PÚBLICO-PRIVADO .}

Siguiendo la brillante contextualización realizada por Serra (1991), en torno a los múltiples escenarios en que podría darse un posible diálogo que no confrontación entre lo público y lo privado, mostramos los escenarios y los correspondientes niveles de diálogo que se pueden producir:

En primer lugar, el escenario ideológico. El que recoge y sintetiza principios y banderas: libertad, justicia, igualdad, progreso... Supuestamente el escenario fundamental y probablemente el escenario más empobrecido en los últimos tiempos como escenario principal del debate.

Un segundo escenario del debate es el escenario político, en el que lo que se discute es, fundamentalmente, el sistema de estructuración y de reparto del poder dentro de la estructura organizacional de la sociedad. Se trata aquí de dirimir qué cuota de poder sobre el conjunto de la sociedad se socializa a través de su cesión al Estado.

Un tercer escenario es el escenario competencial. La discusión se centra en este caso en encontrar la legitimidad que da soporte a la asignación de espacios de competencia. Quién tiene que hacer qué, cuáles son las competencias de cada cual, qué funciones debe cumplir, dónde están los límites de las distintas competencias.

Un cuarto escenario es el escenario productivo. En el que se discute no ya la competencia de cada cual acerca de garantizar una determinada función social, sino la idoneidad para garantizar el proceso de producción del bien o servicio de que se trate.

Un quinto escenario es el escenario gestionario. Cercano al escenario productivo pero distinto. Lo que se discute en él es cómo deben hacerse las cosas sean cuales sean las cosas a hacer. El debate intenta establecer qué reglas del juego garantizan una mayor economía, eficacia y eficiencia. Probablemente, el escenario de debate, diálogo y confrontación más popular, más inmediato, más reactivo y virulento y, en mi opinión, también el más engañoso, ya que parece contener una verdad que aparece como la verdad; a saber, que el sector público no es tan económico ni eficaz ni eficiente como el sector privado y que las cosas alcanzan su optimización, o bien cuando se dejan en manos de estructuras privadas, o bien, peligrosa apreciación, cuando el sector público mimetiza al privado en el ejercicio de sus responsabilidades. Es difícil en este escenario intentar reflexiones racionales, y, en cambio, es, en mi opinión, imprescindible hacerlo para acercarse a soluciones útiles. 


\section{LA EFICACIA EN LA ADMINISTRACIÓN PÚBLICA}

La Constitución Española, en su artículo 103.1, establece que la Administración sirve con objetividad los intereses generales de acuerdo a, entre otros, el principio de eficacia. Este principio, que todavía hasta hace poco era considerado una declaración programática sin expreso valor jurídico, cobra en nuestros días una importancia fundamental, descubriéndose como principio que, en gran medida, va a informar la entera actividad de la Administración Pública.

La importancia y trascendencia de este principio ha sido bien puesta de manifiesto en una obra colectiva que lo analiza y pone en relación con los procesos de privatización. Tal y como Parejo (1989) ha señalado:

«No basta ahora ya al Estado la legitimación que le presta el origen democrático del poder, ni la derivada de la efectividad (en términos tradicionales) de su mando sobre los ciudadanos: le es preciso justificarse permanentemente en la adecuada utilización de los medios puestos a su disposición y la obtención de resultados reales, es decir necesita la legitimación que proviene de la eficacia en la resolución de los problemas sociales». (pág. 162)

En todas las Administraciones se advierte la tendencia y el deseo de evolucionar desde el sistema burocrático al modelo operativo gerencial como camino seguro par mejorar la eficacia en la gestión de las políticas públicas. El principio de eficacia está en la base y origen de todos los procesos de modernización de las estructuras organizativas de las diferentes Administraciones Públicas. Se trata de hacer que la Administración sea menos costosa y más eficiente y que la burocracia abandone su filosofía de complacencia y derechos adquiridos por un enfoque de iniciativa y libertad para actuar. Se pretende rediseñar, reinventar y revitalizar toda la administración. La eficacia trasciende así de su carácter de principio y se convierte en fundamento no ya sólo de la actuación de la Administración, sino de la misma legitimación del ejercicio del gobierno.

La eficacia debe entenderse en relación con otros principios que rigen la actividad de la Administración. El debate sobre la compatibilidad del principio de eficacia con los de legalidad e igualdad viene de muy atrás, si bien forzoso es reconocer que se ha recrudecido tras la constitucionalización del principio. Aunque efectivamente la eficacia es un bien constitucionalmente protegido, este no tiene un carácter absoluto y debe ceder ante otros valores superiores, como, por ejemplo, el principio de igualdad (arts. 14 y 23.2. CE). No puede buscarse en la Administración la eficacia a toda costa si esta supone atentar contra el principio de los ciudadanos ante la ley. 
"Aunque la eficacia de la Administración es un bien constitucional protegido por el artículo 103.1., tal principio es de rango inferior a la igualdad, que es no sólo un derecho individual de los españoles protegible, incluso por vía de amparo (arts. 14 y 53.2. de la CE), sino un principio al que está sometido el legislador (arts. 14 y 9.1. de la $C E$ ), e incluso un valor superior del ordenamiento (art. 1.1 de la CE) ante el cual deben ceder otros de rango inferior, pues es indudable que no puede buscarse la eficacia de la Administración con medidas legislativas que atenten, como ahora ocurre con la enjuiciada, contra la igualdad» (Citado en Etxerraeta, 1995, pág. 48).

Los efectos de todo ello en la gestión de los servicios públicos son importantes ya que, en palabras de Villar (1993), las normas mercantiles no podrán afectar a la igualdad dentro del servicio en sus varias manifestaciones: igualdad en el acceso (universalidad) e igualdad en el funcionamiento (calidad y tarifas). Hablar de eficacia de las Administraciones Públicas implica tomar en consideración los resultados de la acción administrativa, y es bien cierto que el interés por esta cuestión es relativamente nuevo, ya que siempre ha preocupado más la regularidad formal o jurídica del procedimiento que el resultado o producto efectivamente obtenido.

La utilización de un término económico como es el de eficacia como concepto jurídico genera, fruto de la utilización no rigurosa de su contenido estricto, mucha confusión. En la doctrina jurídica, los términos, ambos económicos, de eficacia y eficiencia, son utilizados casi indistintamente, cuando, sin embargo, su contenido es diferente. Se dice incluso en ocasiones que un servicio es eficaz o eficiente porque no es caro y funciona bien ignorando que tal actuación pública puede ser ineficiente en sentido estricto a pesar de su economicidad y buen funcionamiento aparente (Etxerraeta, 1995).

El gestor de un determinado departamento público es eficaz en cuanto, haciendo uso de los medios o recursos que se le señalan, consigue alcanzar los objetivos que también se le especifican en el plan; su gestión será tanto más eficaz cuanto más se aproxime a los objetivos previamente señalados. La eficacia se refiere, pues, al grado de consecución de los objetivos dentro de las restricciones del plan, sin considerar la economía de medios para alcanzarlo. Si, además, y dentro del margen de libertad que le permiten las restricciones del propio plan o programa, consigue alcanzar los objetivos señalados para su área de responsabilidad con un mínimo coste la gestión eficaz sería asimismo eficiente. La eficiencia lleva pues aparejada la consecución de objetivos y la menor utilización de recursos necesario para ello, constituyendo, desde el punto de vista axiológico, un valor jerárquicamente superior al valor de eficacia. 
La eficiencia fue desde el origen el fin más sólido sobre el que los gobiernos conservadores fundaron la ola de privatizaciones. Es pues conveniente que detengamos en él nuestra mirada, siquiera un momento. La medida habitual de la eficiencia es el beneficio antes de impuestos e intereses; este es el beneficio operativo.

El tono de la década en la que nos encontramos viene dado por la cuestión del Estado. ¿Debe éste ampliar su tamaño y ejercer un liderazgo claro, imperioso, en la búsqueda de la prosperidad nacional? $\mathrm{O}$ debe, por el contrario, retirarse a un segundo plano cuidando, entre bambalinas, el establecimiento y cumplimiento de reglas de juego socialmente útiles?

El derrumbe de las economías de dirección central ha debilitado de tal modo los ánimos de quienes propiciaban el protagonismo del Estado en Occidente que se hace difícil no sólo conocer su pensamiento sino identificar a los partidarios claros de su expansión. Pervive, con todo, un puñado de defensores de un gran Estado de Bienestar. El debate más vivo y las polémicas más interesantes se están produciendo, sin embargo, entre los defensores de una vuelta fundamental a la iniciativa privada como hemos comprobado anteriormente. $Y$, en este campo, también el desmoronamiento de las economías planificadas ha tenido una incidencia profunda. ¿Cómo desestatificar con eficacia y mantenerse en los márgenes políticamente manejables? ¿Cuáles son las condiciones necesarias para una privatización sostenida sin traumatismos desestabilizadores? En este campo, las preguntas se enredan como racimos de cerezas.

Los argumentos más escépticos hacia las privatizaciones, fin primordial que persigue la eficiencia, son de distinto tipo. Sostienen unos que la competencia es de la más alta relevancia para que tengan las privatizaciones alguna probabilidad de éxito. Que se mantenga la libertad de entrada en el sector y la rivalidad, al menos potencial, entre los oferentes es crucial para maximizar los beneficios del consumidor, tanto como para garantizar una efectiva limitación del poder de monopolio de los nuevos dueños (Beesley, 1993). Opera, pues, el grado de competencia como indicador del nivel de éxito alcanzado por las privatizaciones. Es la competencia la condición necesaria de reducción de costes en los procesos de privatización. Bien lo habían detectado Millward y Parker (1983) en los comienzos de la década pasada .

Algunos autores han hallado, incluso, episodios y pronosticado privatizaciones en los que las empresas perceptoras de compañías privatizadas, operando en régimen de monopolio, parecen trabajar con menor eficiencia. Pero quien dice privatizaciones dice contratos externos. La contratación externa, aún admitiendo que la propiedad privada genera mayores incentivos para la eficiencia que otros sistemas 
de propiedad, puede suceder que no se disponga de información adecuada para detectar la oferta más barata. Pero existe la posibilidad de oferta temeraria, rebajando los precios a corto en la presentación de la oferta, con el fin de asegurar una posición de monopolio a largo plazo. Veamos algunas consideraciones sobre este fenómeno en los servicios sociales, especialmente en la tan utilizada contratación externa.

El incremento de la contratación externa como forma de gestión indirecta de Servicios Públicos en las áreas de Bienestar Social es un hecho evidente en determinadas áreas de la Administración y que aumenta cada día; pero, a pesar de su desarrollo, nos falta todavía aclarar muchos temas para poder argumentar empíricamente que de esta forma se mejora el servicio que recibe el ciudadano. Tanto las Administraciones como los contratistas han de profundizar en las vertientes jurídico-administrativa y conceptual para poder mejorar la calidad.

Una reflexión metodológica sobre la contratación externa de los servicios personales tendría que poder contestar a las siguientes cuestiones, que, no por clásicas, son menos necesarias de conocer en profundidad: ¿Qué razones llevan a optar por esta forma de gestión? ¿Para qué servicios en concreto, es decir, por qué para unos sí y no para otros? ¿Responder a un criterio de descentralización o de importancia territorial, aún en el mismo municipio, por ejemplo? ¿Quién decide si se realizará en todo el territorio o en una parte? ¿Qué porcentajes de la gestión se aplicará? ¿Se realiza con todo el servicio o solamente una parte? ¿Por qué, y en base a qué criterios? ¿Quién y cómo se definen los criterios temporales, ligados a la evaluación y los criterios ambientales, ligados a las posibilidades del entorno de crear una dinámica de mercado con capacidades de gestión? ¿Qué formas jurídicas se utilizarán y cuál ha de ser el contenido del contrato: qué cláusulas técnicas ha de tener para garantizar la calidad? ¿A quién de las diferentes posibilidades de contratistas, a cuáles se adjudicarán qué servicios? ¿Para quién serán los beneficios de la contrata directos e indirectos? y ¿Quiénes serán los beneficiarios del servicio?.

Como vemos, hay muchas preguntas que forman parte de un proceso metodológico que a veces los intereses políticos y las prisas y apremios administrativos dejan su respuesta en un segundo plano, lo que no quiere decir que se estigmatice la contratación externa, sino que simplemente necesita que deban ser, al menos desde nuestro punto de vista, debidamente contemplados. La contratación externa puede añadir determinados valores al servicio, derivados de la propia forma de gestión, que es importante tener presentes a la hora de optar por ella: determinados contratistas pueden tener un mayor conocimiento del terreno, lo cual puede revertir en un incremento de la eficacia; puede aportar una mayor capacidad de innovación; representa un incremento 
de la participación social, ya que se están implicando agentes diferentes a la Administración en la responsabilidad de su prestación; puede aportar una mayor eficiencia en la gestión del servicio y permite la comparación de la gestión y de los costes entre los diferentes contratistas.

\subsection{Empresa pública versus empresa priva}

Cuando se afirma que la empresa privada es más eficiente al reducir los costes de los servicios por concentrar más la responsabilidad en quien toma las decisiones (arriesga la propia riqueza, se somete a las presiones del mercado y soporta el riesgo de ser expulsado del mercado), lo que se está poniendo de manifiesto no es una ineficiencia natural de la empresa pública por razón de su propiedad, sino la ausencia de unos criterios de responsabilidad en la misma (o en los políticos que la controlan) que den lugar a unos resultados similares a los del mercado privado. La cuestión, por tanto, está más bien en determinar criterios de responsabilidad eficiente en los políticos, de tal forma que estos soporten también los «costes» de su gestión (Cainzos, 1991).

Bajo la oleada de argumentos que suscitaron los procesos privatizadores, se halla la comparación de eficiencias relativas y otros parámetros de empresas públicas y privadas. Un estudio muy conocido, que ha llegado a ser paradígmático de este tipo de equiparaciones, es el de David G. Davies, citado por Steve H. Hanke (1991) sobre los méritos relativos de compañías australianas, unas públicas y otras privada.

Al discutir los méritos relativos de uno y otro esquema institucional de empresa se ha subrayado diversos parámetros en los que la empresa privada ofrece ventaja notoria. El interesante artículo de Hanke hace un recuento de los principales trabajos comparativos de la eficacia relativa de la misma empresa en el sector público y en el privado. Sigámosle.

Refiere en primer lugar el estudio de Robert, W. Poole en el cual se han presentado notables ahorros en diversos servicios como ambulancias, controladores aéreos, protección contra incendios y las prisiones respectivamente gestionadas por el sector público o por manos privadas. Otros autores han hallado costes significativamente menores en empresas eléctricas, guarderías y otras empresas de servicios. Semejante hallazgo fue obtenido, por W. Clarkson y William Rushing, respecto a la superior eficacia de la administración hospilataria en establecimientos sanitarios y públicos. Cita Hanke un interesante estudio de W. Mark Crain y Ashar Zardhooki en el que los costes de una muestra de 24 empresas de aguas privadas y 88 públicas de suministro de aguas 
resultaron significativamente más altos (un 25 por cien más) en éstas últimas. ¿Diagnóstico?, menor productividad del factor trabajo e infrautilización del equipo en las empresas públicas. El propio Hanke halló una práctica de subvención a clientes determinados a cargo de precios más altos cobrados a otros en las públicas. Aunque los estudios citados por Hanke parecen apoyar la mayor eficacia de la empresa pública -eficacia económica, prescindiendo de objetivos sociales, naturalmente- no falta evidencia empírica en sentido contrario.

Los razonamientos relativos a la eficiencia actúan según dos puntos de vista, el de la prestación del bienestar y el del crecimiento. De acuerdo con el primero, se dice que el bienestar alienta el despilfarro tanto de los consumidores como de los productores. Los primeros no están sometidos a la disciplina del pago directo y los segundos no perciben el estímulo de la competencia. Sin embargo, los mercados privados del bienestar pueden adolocer de problemas parecidos. Los consumidores pueden verse sometidos a abusos, dada la importancia de disponer de conocimientos técnicos, problema que es especialmente grave en los campos de la medicina y la enseñanza. Los mercados competitivos pueden desembocar en monopolios. Los servicios públicos pueden ser más eficientes en el cumplimiento de sus objetivos al centrar sus recursos en cubrir necesidades, ya que no dependen de las pautas de los precios, en casos en los que el poder adquisitivo puede no estar distribuido adecuadamente. Por consiguiente, el argumento de la eficiciencia para la privatización supone la existencia de mecanismos para la redistribución de la renta o para garantizar el funcionamiento eficaz y no estigmatizante de un sistema de previsión pública muy selectivo.

Los estudios empíricos tampoco llegan a ninguna conclusión. Se dispone de escasas pruebas sobre la eficiencia en el ámbito del bienestar. Spann, por ejemplo, en un estudio sobre hospitales públicos, voluntarios y lucrativos en los Estados Unidos llega a la conclusión de que, aparentemente, entre los tres tipos hay poca diferencia de calidad. En el estudio de los datos disponibles realizado por Millward (1989), a principios de los ochenta, se llega a conclusiones contradictorias.

\subsection{Eficiencia y competencia.}

Existe una alta evidencia empírica de que la competencia es la forma más eficaz para fomentar la eficiencia productiva (Donahue, 1991). La competencia impulsa a los gestores a acercarse lo máximo a los límites de la producción. Además, les ofrece a los representantes del capital la información relevante que les sirve para controlar mejor sus 
actividades. Todo ello hace que la competencia favorezca asimismo la eficiencia en la asignación (Yarrow, 1989).

Si unos gestores no logran reducir los costes, aumentar la calidad, etc., en definitiva, la eficiencia, en una situación de competencia, la propia supervivencia de la empresa y de sus mismos puestos de trabajo están en peligro. Sin embargo, tampoco en todos los casos se puede defender la máxima de que cuanto más competencia haya, mayor es la eficiencia que se logra. Así, en determinados sectores, por las especiales características de la actividad a realizar, puede no ser la más conveniente la alternativa que ofrezca el máximo de competitividad.

Salvo esos casos particulares se puede sostener como cierto que la mejor forma de que coincidan los beneficios y el interés público es que el bien o servicio privatizado esté en un mercado competitivo. Hace falta la competencia de otras empresas para disciplinar el comportamiento de los gestores. Sin ella, será posiblemente continuamente necesaria la actuación pública (Goodman, 1994).

Ocurre que una organización privada que se mueve en un ámbito monopolístico pierde la tensión organizativa que el mundo competitivo conlleva decreciendo su capacidad innovadora y de búsqueda permanente de la reducción de costes y del aumento de la calidad como razón de supervivencia. Los resultados producidos por los monopolios de propiedad privada distan mucho de ser considerados como de alto rendimiento. Como explica Martín Mateo (1994), si la competencia es escasa, las empresas privadas sometidas a regulación no se comportan mejor que las públicas, quizás peor. En un contexto no competitivo, las privatizaciones probablemente serán netamente perjudiciales.

Pero ¿qué sucede si la empresa privatizable opera en condiciones de monopolio natural? Basta para conseguir evitar ambos daños de un solo golpe con que la subasta se realice sobre la base de los precios a cobrar y del servicio que se vaya a dar por parte del mejor postor. Se trataría, en otras palabras, de subastar el derecho, estipulando nítidamente la relación calidad-precio del output futuro. Esta subasta garantizaría, con toda probabilidad, un volumen de producción y un precio muy próximo, cuando no igual, al de la empresa precio aceptante en el mercado competitivo. Aunque mucho depende, es de reconocer, de la correcta estipulación del precio de venta y calidad exigido al futuro oferente victorioso en la puja. No consiste, pues, la subasta de la concesión en concedérselo al pretendiente que está dispuesto a pagar un precio más alto por la susodicha concesión. 


\section{LA IMPORTACIÓN DE TÉCNICAS DEL SECTOR PRIVADO}

Los dos problemas capitales con los que se encuentran las Administraciones Públicas son, por una parte, el llamado déficit de niveles de eficiencia y, por otra, la siempre difícil adaptación de los procesos de gestión importados de la empresa privada; pero, avanzando más en esta idea, hay que señalar que la importación de técnicas del sector privado al sector público debe contemplar los fines de las Administraciones Públicas y de las organizaciones a ellas vinculadas. La aplicación de una misma técnica de gestión en una empresa pública y en una privada vendrá condicionada por el fin que cada una de ellas tenga asignado. Además de esta limitación, hay que añadir la más transcendente y que se refiere a que la importación de técnicas privadas sólo se puede realizar en la zona operacional, lo cual resulta de gran interés para los servicios sociales. Las dos limitaciones anteriores, añadidas a los principios de la actuación de lo público, marcan los límites de actuación entre lo público y lo privado.

Con frecuencia, se afirma que la Administración pública es ineficiente por sí misma. Esto no es decir cosa alguna si nos estamos refiriendo a la zona decisional, puesto que su actividad no es equiparable a la actividad privada. Por eso, cuando se afirma que la política no utiliza criterios racionales, se está diciendo la verdad porque la lógica política es una lógica compleja en la que se implican a muchos actores de diversa naturaleza, lo que permite que se mantenga en equilibrio el Estado. Es claro que esto no es trasladable al sector privado.

Estas reflexiones hay que completarlas con el hecho de que el sector público realiza sus actividades en régimen monopólico en muchas ocasiones, debido precisamente a la naturaleza ya descrita de la actividad. Por ello, para evaluar los resultados en la prestación de los servicios, lo público frente a lo privado tiene su importancia, pero lo competitivo frente a lo no competitivo resulta habitualmente más importante. Y esto es perfectamente trasladable a las actividades monopólicas u oligopólicas del sector privado.

Otra limitación a la importación de técnicas a la Administración Pública proviene del hecho de que en la empresa privada, cuando se realizan tareas públicas, se traslada el mandato externo de producir bienes y servicios a un mandato interno de generar ingresos y limitar costos. Esto no es posible hacerlo con carácter general en la Administración pública, ya que persigue simultáneamente otros objetivos, por ello el producto social y político de dos organizaciones, una pública y otra privada, realizando las dos una misma actividad, debe ser, en principio, distinto. Si no lo es, especialmente en el caso de los servicios sociales, habrá que pensar que el interés general ha excluido de su 
atención a ciertas capas de la sociedad, precisamente las que no han conseguido que sus intereses se publifiquen y las que tampoco han sido merecedoras de que el Estado sea su valedor.

\section{LOS PROCESOS PRIVATIZADORES}

Un elemento esencial de una política eficaz sobre la competencia $y$, en definitiva, de una privatización en su concepto más estricto, es la regulación (Hemming y Mansoor, 1994), hasta el punto de que es posible afirmar que regulación y privatización van indisolublemente unidas. Debe esto ser así so pena, en caso contrario, de pérdida de los grandes avances que las sociedades occidentales han logrado, reemplazando el monopolio jerárquico de la Administración pública por la mano invisible del mercado, en la versión más radical de las políticas que defienden el protagonismo del mercado.

Pues bien, no es concebible esa regulación sin la concreción y materialización del interés general en ámbitos concretos y sin la determinación de los derechos de los usuarios.

Esta concreción y materialización es además necesaria para incluso medir y ponderar la decisión de privatización e incluso su valoración una vez desarrollada. En palabras de Paul Starr (1995).

«La privatización tiene sus límites, no siempre da el mejor resultado»

«Mejor no puede significar solamente lo más barato o lo más eficaz, siendo necesario ponderar las cuestiones relacionadas con la justicia, la seguridad y la ciudadanía para una evaluación razonable de las alternativas». (pág. 231)

Así, encontramos que la privatización de los servicios públicos halla otra frontera derivada de la propia delimitación entre la sociedad y el Estado. Efectivamente, para amplias capas de la sociedad española, sólo el Estado, en sus diversos niveles organizativos, representa la garantía de hacer valer sus derechos. Por ello, sería una grave irresponsabilidad el pretender que el mercado regulase dichas capas, puesto que éstas se caracterizan por haber sido excluidas del mismo. Claro es que la privatización ha logrado poner en primer lugar la importancia de la gestión y la ha Ilenado de contenido político. Por ello, en los servicios públicos de la zona operativa es necesario la aplicación de técnicas de gestión que persigan la eficiencia, aunque con las cautelas anteriormente señaladas.

Pero el Estado no se puede desentender, ni siquiera en el caso de que se cumplan los requisitos señalados anteriormente, de una activi- 
dad que ahora pasa al sector privado. Ello es debido a las consecuencias sociales de toda actividad empresarial y, fundamentalmente, a que ahora ese sector privado realiza, en medida variable, funciones públicas. Por ello, no debe ser indiferente a los efectos del Estado que el logro de una mayor eficiencia en la prestación de un servicio privatizado se haga a costa de un significativo descenso del salario o de una reducción en los niveles de prestación. Podemos encontrar ejemplos periódicos en las huelgas de las contratas públicas en sectores como el de limpieza de los hospitales públicos, el de recogida de basuras y limpieza viaria, etc.

Por todo ello, se puede decir que la privatización exige un Estado fuerte. Una privatización extensa sólo podrá producirse si queda asegurado el fin esencial y ello pone el énfasis en el control que debe ejercer la Administración sobre las actividades privatizadas. En conclusión, la justificación de la privatización acaba remitiéndonos al criterio de la eficiencia y, preferiblemente, para aquellas actividades donde sea posible la competencia. Esto significa la transformación de una parte de la actividad estatal, en caso de que se produjera una privatización significativa del aparato administrativo, que pasaría de ser prestadora a garante de los fines políticos de los servicios públicos, gestionados ahora de forma privada.

\section{MODALIDADES DE RELACIÓN PÚBLICO-PRIVADO EN LA PRESTACIÓN DE SERVICIOS PÚBLICOS}

Es importante subrayar que las características definitorias del marco institucional y del tipo de incentivos a establecer variarán sensiblemente en función de: a) la importancia que se quiera atribuir a la gestión directa a cargo de la Administración en la prestación de un determinado servicio público, y b) del tipo de relación Administraciónentidades privadas que se quiera establecer.

De forma esquemática, podemos contemplar, bajo la orientación de Mendoza (1991), dos tipos de relación público-privado cualitativamente diferentes: la mercantil y la de cooperación. La relación mercantil es del tipo cliente-proveedor. El papel asignado a las organizaciones privadas (con ánimo de lucro o sin él) es el de la ejecución de una política cuyos objetivos habrán sido predeterminados por la Administración sin la intervención de dichas organizaciones. Lo único que se contrata a dichas entidades privadas es, pues, su capacidad de prestar un determinado servicio a cambio de una contrapartida económica.

Ante lo anterior es importante señalar dos aspectos. Primero, que la implicación de los agentes privados en la prestación de servicios 
públicos tiene aquí un carácter estrictamente instrumental y bajo una lógica muy próxima al control jerárquico «quien paga, manda»). Segundo, en este tipo de relación el riesgo y la responsabilidad no son asumidos por igual entre el sector público y el privado. Mientras el primero debe responder tanto de la idoneidad del diseño de la política como de su implementación, los agentes privados sólo responderán -lógicamente- de los aspectos materiales relacionados con la prestación de aquella parte del servicio público que les ha sido encomenda$\mathrm{da} /$ contratada.

Por contra, la relación de cooperación plantea un escenario distinto. Aquí la Administración busca aprovechar los recursos, conocimientos y experiencias ya existentes de las organizaciones privadas a través de proyectos comunes, en donde el sector público y el privado participan en la detección de necesidades y/o en el diseño de los programas de actuación, asumiendo ambos la responsabilidad por los resultados.

La relación de cooperación constituye un mecanismo de participación directa y de implicación de la sociedad civil en la resolución de una serie de problemas sociales que le afectan. Ahora bien, este tipo de relación comporta retos tanto para el sector público como para el privado. Para el sector privado, porque el corolario de la co-responsabilidad es la co-financiación. No puede esperarse, en este contexto, que sea el sector público quien aporte la totalidad de los recursos monetarios necesarios.

Para el sector público, la relación de cooperación también comporta retos (Mendoza, 1991). Primero, porque supone abrir la discusión sobre los objetivos de las políticas y programas de actuación e incorporar en el proceso a estas organizaciones. Segundo, porque ello comporta que el «protagonismo» institucional pierda relieve y lo ganen, en cambio, los objetivos perseguidos. Lo importante ya no es el quién sino el qué se hace, y cuáles son las respuestas que se dan a un determinado problema social. Tercero, en una sociedad democrática y adulta, cooperación y crítica no son excluyentes. No por realizar proyectos conjuntos debe esperarse de las entidades privadas que renuncien a denunciar aquellas situaciones sociales menos gratas y que los poderes públicos y la propia sociedad prefieren ignorar (como el caso de la pobreza en las grandes ciudades españolas).

En resumen, Administración, sociedad civil y mercado son elementos que pueden articularse de diversas maneras en la prestación de servicios públicos. No existe, pues, una única modalidad de contratación externa de los servicios públicos, sino diferentes posibilidades en función del contexto (de concurrencia o no) y del tipo de relación público-privado (mercantil o de cooperación). 
La privatización es un proceso que se va a servir de múltiples técnicas. Existen bastantes guías, y cada una parte de un lugar para llegar a otro de su particular interés, con la consiguiente carga ideológica. Desde nuestra óptica, compartida con Etxezarreta (1995), seguimos las propuestas de Pirie (1990), por su amplitud, que sobrepasa con creces el objetivo de este artículo, pero únicamente señalamos aquellas técnicas más conocidas y de aplicación más efectiva en el ámbito de los servicios sociales.

1. Técnicas dirigidas a la privatización de la producción.

La Administración mediante la utilización de estas técnicas va a permanecer en la responsabilidad de la determinación de la prestación entregando a la iniciativa privada la elaboración de la misma.

a) Contratación del servicio a una empresa privada.

Se trata de la asignación de la producción del servicio a una empresa privada a la que se paga con recursos públicos. La Administración no elabora pero sí garantiza la oferta.

Con la producción a cargo del sector privado se reintroducen las leyes del mercado desapareciendo todas las prácticas restrictivas y de servicios controlados por los trabajadores y apareciendo un clima de competitividad. Las empresas se mantienen competitivas en precios y calidad mientras tratan de conseguir el contrato y mantenerlo. Los costes descienden porque recursos humanos y materiales son utilizados eficientemente.

Se debe asegurar un tratamiento preferente a los trabajadores existentes de forma previa a la aparición del gestor privado y que sobre éste no exista ninguna duda acerca de su capacidad para gestionar la producción correcta del servicio.

Los resultados que esta técnica viene continuamente ofreciendo son muy importantes.

b) Promoción de instituciones alternativas.

En un campo en el que, o no hay de por sí oferta privada o siempre ha dominado la pública, la opinión pública no ve la posibilidad de que exista una oferta privada válida. Encuentra difícil la concepción de alternativas.

La constitución de instituciones alternativas es capital por su carácter ejemplificador, debiendo la Administración limitarse a la promoción de estas instituciones al deber ser éstas de carácter privado.

El crecimiento de instituciones que representen una alternativa de oferta privada no sólo da capacidad de elección a los consumidores sino que también elimina el papel de la Administración como único empleador en ese campo. 
El éxito de instituciones de esta naturaleza proporciona poderosos apoyos a posteriores tendencias hacia la privatización.

2. Técnicas dirigidas a la privatización de la financiación.

Así como la producción de bienes y servicios puede estar en manos del sector público o del sector privado, así también la financiación de la producción puede estar en cualquiera de los dos sectores.

a) Cobro de los servicios.

El cobro de un precio por un servicio que anteriormente era gratuito es un ejemplo de traslación de la financiación al sector privado mientras continúa en el sector público la producción. El sistema de precios directos evita un exceso de demanda derivado de su carácter de libre, demanda que puede llegar a ser irracionalmente alta. La resistencia social y política a la introducción de precios allí donde no los había o incluso a su incremento introduce una dificultad operativa a esta técnica. Ejemplos los tenemos en el servicio de ayuda a domicilio o teleasistencia.

b) Fomento del abandono de la provisión pública.

La financiación pública hace que ciertos servicios permanezcan cerrados a la iniciativa privada como si de mercados monopolísticos se tratara. En ciertos de estos casos existen proyectos alternativos de carácter privado que son sólo alternativas para los que tienen un nivel de renta suficiente para pagar por esos servicios privados en campos en los que existe una provisión pública. La extensión de los servicios prestados por la oferta privada, con precios cada vez más atractivos para los potenciales clientes hará que paulatinamente la Administración pueda tomar medidas positivas para fomentar el abandono de la provisión pública.

3. Técnicas de privatización por la demanda

Consiste genéricamente en trasladar al usuario el poder de decisión de la elección.

a) Utilización de cheques y/o bonos.

En lugar de ofrecer al público servicios gratuitos que han sido financiados con ingresos impositivos, se trata de ofrecerles cheques, «Vouchers», con que pagar el servicio. La utilización de cheques en lugar de dinero está pensada para asegurar que los recursos se gastarán en el servicio y no se emplearán en otra cosa al arbitrio de sus beneficiarios.

La idea que late tras esta técnica es la de la capacidad de elección del consumidor. Las instituciones públicas que compitan en el mercado tendrían que orientarse hacia los consumidores si desean obtener suficientes cheques para su financiación, viéndose en definitiva envueltas en la dinámica del mercado. Los cheques sirven 
también como una forma de dirigir las subvenciones a los propios necesitados en lugar de hacia los productores del servicio mismo. Están así destinados a la demanda y no a la oferta. Así, la Administración puede además garantizar el poder de compra de personas que necesitan ayuda, pudiendo la oferta de servicios permanecer en manos privadas. Son ejemplos prácticos el bonotaxi para discapacitados con graves problemas de movilidad, cheques para residencias de tercera edad, tratamientos rehabilitadores o terapéuticos, prestaciones asistenciales en el hogar en el que asistan enfermos de Alzheimer u otro tipo de demencias. El 27 de noviembre ha tenido lugar en el IMSERSO una Jornadas relativa al estudio y análisis de los sistemas de utilización de cheques como pago de servicios, lo que pone de manifiesto el interés de la Administración por esta modalidad de cara al futuro de las relaciones con las empresas y la iniciativa social que presta servicios sociales finalistas.

b) Derecho a la opción privada.

Se trata de conceder al público el derecho a optar por la prestación privada del servicio, permaneciendo el pago del mismo en manos públicas. Ello ofrece un mayor campo de actuación a la competencia. La implementación de un derecho a la opción por una oferta privada es una de las nuevas armas en el arsenal de la privatización. También es una de las más prometedoras en tanto incrementa la capacidad de elección disponible para el público en general. La oposición a este procedimiento ha de basarse en el supuesto de que tal oportunidad de elección no ha de permitirse y que, por tanto, el público tiene que estar obligado a depender únicamente del sector público, a la calidad y velocidad que él impone. Políticamente esta es una posición débil, con la mayoría de los grupos de interés alineados por el lado de la extensión de la capacidad de elección.

Corrigiendo el borrador de este artículo se ha producido en nuestro país un importante debate en torno a una nueva modalidad de privatización, que no por conocida era menos esperada, nos referimos a la instauración de las fundaciones para gestionar los hospitales públicos. Y que, como cabría esperar, ha provocado una importante discusión sobre su implantación entre los que defienden que se trata de un mecanismo para favorecer la gestión y, por tanto, aumentar los niveles de eficacia y eficiencia de los hospitales y aquellos que denuncian esta operación como una privatización encubierta, señalando además que se ha producido sin debate público, quedando reflejada su implantación en la Ley de acompañamiento de los presupuestos para 1999, por la puerta falsa, dirían algunos otros. 
Para abordar adecuadamente el espinoso argumento de lo público y lo privado, y tras haber expuesto algunas consideraciones sobre una de las cuestiones en las que se deposita el debate: la eficiencia. Nos queda abordar dos aspectos tan significativos como éste: la modernización de la Administración y de todos sus procesos administrativos y de recursos humanos y el desarrollo de la cultura de la calidad en el contexto de la Administración Pública y, de una manera muy especial, en servicios sociales.

\section{LA MODERNIZACIÓN DE LA ADMINISTRACIÓN}

Las distintas Administraciones públicas de los países desarrollados están implicadas en una serie de profundos cambios y transformaciones con los que, en principio, tratan de mejorar la prestación de servicios públicos, así como adaptarse a los cambios de entorno existentes en las sociedades contemporáneas. El término modernización se utiliza en España y en algún otro país como paraguas conceptualizador bajo el que se acogen todo este conjunto de fenómenos de adaptación. Fenómenos que parecen intentar alumbrar un nuevo paradigma de gestión pública, una nueva forma de pensar sobre la acción de gobernar y sobre cómo ha de materializarse ésta.

Aquí defendemos que la modernización sólo se puede comprender en el marco de los grandes cambios políticos y sociales que nuestras sociedades están viviendo, pero, sin obviar, en el análisis, las peculiaridades de cada Estado implicado. Ello implica la aceptación de tres principios, utilizando las consideraciones de Alvarado (1998). Prime$r o$, que las variables que operan en el proceso de cambio no son sólo económicas; hay variables económicas y sociales en el entorno externo y, sin lugar a dudas, factores internos idiosincráticos, como la cultura política y cívica, el liderazgo o la estructura del sistema político (Huntington, 1971), que matizan o adaptan las influencias extemas al país y a cada circunstancia específica. Segundo, que la fuente principal de cambio son los cambios sociales y económicos que se producen fuera del sistema político. Dichos cambios impactan en la estabilidad del sistema y la consecución de un relativo equilibrio se produce en función de la participación social en la respuesta. Si dicha participación se logra institucionalizar, es decir, si el sistema consigue procesar de forma coherente la nueva estructura de demandas, se logrará la nueva y frágil estabilidad (Huntington, 1971). Tercero, que dado que las variables que actúan en el proceso son numerosas, cualquier reduccionismo es altamente peligroso para la adecuada respuesta final; de ahí que, desde una perspectiva científica, se tenga que intentar denun- 
ciar los reduccionismos ideológicos en la selección de las causas. Las causas que se estiman como influyentes e incluso determinantes del cambio son:

1. La radicalización de los rasgos de la modernidad, con la consiguiente fragilidad de las relaciones causa-efecto en un mundo cada vez más complejo e interdependiente y la dificultad para los gobiernos de controlar esta maquinaria tecnológica y sus efectos no deseados (Giddens, 1994).

2. Los procesos sociales y económicos como la globalización de los problemas y soluciones, el creciente peso de la opinión pública en el marco de la sociedad mediática y el imparable desarrollo de la sociedad del conocimiento, de la investigación y de la tecnología, con sus tremendas implicaciones sobre las organizaciones y sus empleados.

3. El desarrollo de las expectativas sociales frente a lo público, sobre todo en los países desarrollados, fenómeno que, unido a los procesos de elección democráticos y a su incapacidad para rechazar demandas, provoca un exceso de inputs sobre las maquinarias administrativas, las cuales se muestran incapaces de procesarlos en un entorno de conciencia de la escasez de recursos.

4. El cambio en el entorno económico, con unos mercados financieros internacionales con capacidad para condicionar las políticas económicas, provocando la pérdida de autonomía de las autoridades nacionales en la definición de las citadas políticas. Y un cambio en el pensamiento económico, con la progresiva retirada del cheque en blanco keynesiano a los gobiernos, los cuales tienen que, cada vez con mayor rigor, explicar en términos de eficacia sus actuaciones.

Como consecuencia de las causas a que antes hemos hecho referencia, se reflejan unos efectos que acertadamente nos señala Alvarado (1998): la Administración está, en primer lugar, fuertemente cuestionada como centro de definición del interés general de la sociedad. También está cuestionada como organización eficiente y como organización eficaz en la prestación de servicios de calidad a sus clientes. En segundo lugar, ha perdido sus límites tradicionales, siendo una organización difusa; así, se han desarrollado enormemente sus líneas de colaboración con las empresas privadas y las organizaciones no gubernamentales -privatizaciones, contracting out, desregulaciones, etc.-, lo cual hace difícil saber dónde empieza o acaba la Administración; al tiempo, continúa generando agencias autónomas o semiautónomas para la solución de problemas novedosos pero, también, hace desaparecer entes instrumentales propios de la época de apogeo del welfare state, como las empresas públicas; finalmente, se enfrenta a procesos de descentralización territorial e internacionaliza- 
ción, con la consiguiente creación de nuevos gobiernos intermedios hacia dentro, mientras, hacia afuera, pierde capacidad de toma de decisiones autónomas con el desarrollo de diferentes órganos internacionales o la revitalización de los anteriormente existentes. Tercero, se encuentra sometida a diversos debates sin que sea sencillo hallar soluciones a los mismos; así, no tiene claro si la gestión pública es un proceso técnico o político, si basta con generar respuestas de gestión importadas del sector privado o si es necesario reciclarlas con los valores propios de lo público, si es necesario desarrollar habilidades gerenciales o una mayor sensibilidad ética, si hay que dar empowerment a los empleados públicos o hay que desarrollar políticas neotayloristas centradas en medir rendimientos y en reducir plantillas, o bien, si es imprescindible hacer todo ello a la vez, intentando encontrar en cada caso el equilibrio preciso.

Pero en el fenómeno de la modernización, los empleados públicos tienen, desde nuestro particular e implicado punto de vista, un papel importante que no debemos ni queremos olvidar. Así que deseamos preguntar por el papel que pueden jugar los empleados públicos ante las demandas críticas de falta de eficiencia, eficacia y otras, a veces menos precisas andanadas, que lo único que persiguen es enmascarar el auténtico problema de la Administración que siempre se están poniendo parches y se proponen soluciones y remedios parciales. No se toma y se analiza el problema en su totalidad, abarcando todas las posibles salidas y con la colaboración de los interesados.

Se espera que los empleados públicos sean fieles cumplidores de los mandatos políticos. Su deber es cumplir los propósitos establecidos en los mandatos con la máxima eficacia y eficiencia. Se supone que los empleados públicos son grandes conocedores del campo en el que trabajan, es decir, que dominan los principales programas operativos que se pueden utilizar para conseguir los resultados deseados y que saben cuándo su actuación es de calidad y eficacia. También se espera de ellos que sean administrativamente competentes, que sean capaces de diseñar estructuras organizativas y realizar mejoras para que la organización tenga un rendimiento más eficaz y eficiente, y que administren los recursos financieros y humanos que les han confiado, para demostrar que no ha existido menoscabo, derroche o uso indebido de los recursos públicos.

Esta doctrina, criticada y estudiada con gran acierto por Moore (1998), genera una forma de pensar característica entre los empleados del sector público: la forma de pensar de administradores o burócratas y no de emprendedores, líderes o directivos. 'Su orientación es descendente, hacia el control fiable de las operaciones organizativas más que hacia afuera, hacia el logro de resultados; o ascendente, hacia la 
renegociación del mandato político. En lugar de contemplar su tarea como la iniciación o el impulso del cambio, la suelen concebir como el mantenimiento de una misión institucionalizada frente a los constantes cambios políticos. Su principal objetivo de gestión es perfeccionar las operaciones de sus organizaciones en su función tradicional, en lugar de innovar para cambiar dicha función o aumentar su valor para el Estado.

Reflejando los vientos de cambio en el pensamiento directivo que ahora invaden tanto el sector público corno el privado, la imaginación de bastantes empleados públicos con cargos directivos (especialmente significativo es este elemento entre los de servicios sociales que han tenido que levantar organizaciones sin ningún tipo de ayuda) va más allá de su mandato tradicional y de su instinto, poniendo de manifiesto un espíritu emprendedor. Abandonan las restricciones convencionales de su trabajo para imaginar qué puede hacer al respecto. En lugar de ver las nuevas demandas sociales como un problema, las consideran como una oportunidad. Tienen la sensación de que pueden crear algún valor para, al menos, algunos de los ciudadanos si se les permite trabajar a otro ritmo, y no necesariamente el que marcan las empresas privadas.

En este sentido, el empleado público, desde nuestra perspectiva, debe empezar a pensar tal y como la sociedad espera que piense un ejecutivo del sector privado, o sea, centrándose en la cuestión de si el conjunto de activos y capacidades de su institución se puede utilizar para crear un valor añadido para el contexto interventivo en que trabaja. No da por supuesto que sus recursos sean fijos, o que su misión esté restringida y sea inmutable, o que su organización sólo sea capaz de producir lo que está produciendo actualmente, sino que utiliza su imaginación para pensar cómo podría reposicionar y adaptar su organización para satisfacer las nuevas necesidades de los ciudadanos elegidos como población objetivo. En resumen, debe pensar como un líder emprendedor.

Reconciliar el deseo de que el proceso político determine lo que es valioso que el sector público produzca, reconociendo que el juego democrático es vulnerable a diferentes tipos de corrupción, ha constituido el reto persistente de quienes han querido ofrecer una teoría de la gestión pública en democracia. Con el tiempo, hemos confiado en diferentes conceptos como estándares para definir los propósitos directivos. De aquí, que sea de enorme interés conseguir objetivos de manera eficiente y eficaz. Durante la mayor parte de nuestra historia reciente, la concepción predominante ha consistido en que los empleados públicos deben trabajar para conseguir los objetivos marcados por los mandatos legislativos de la manera más eficaz y eficiente posible. 
Para aquellos que consideran que la política es una vía para crear la voluntad colectiva, y que ven en el sistema democrático la mejor respuesta al problema de reconciliar los intereses individuales y colectivos, no es sorprendente que dejen decidir al proceso político lo que es o no valioso producir con recursos públicos. Ningún otro procedimiento es coherente con los principios de la democracia.

Pero, para aquellos que desconfían de la integridad o utilidad de los procesos políticos, la idea de que el valor público se debe definir políticamente es difícil de aceptar. Han visto demasiada corrupción para confiar la determinación del valor público al proceso político. Como mínimo, dichos críticos quieren garantías de que el proceso político acepta los límites de la acción pública o cumple unos mínimos estándares de justicia y competencia en las deliberaciones que producen los mandatos. Alternativamente, preferirán procesos más objetivos para determinar el valor de la actividad pública y alguna plataforma para confrontar los procesos políticos con dicha información objetiva. (Moore, 1998)

Sin embargo, la política también genera desconfianza en nuestra cultura, y así han emergido plataformas para disciplinar y racionalizar el proceso democrático. Dicha plataforma fue establecida según un nuevo tipo de conocimiento. Mientras que la teoría tradicional de la administración pública reconoció el conocimiento sustantivo y administrativo de los profesionales (desarrollado a través de la experiencia profesional y la educación), la nueva formulación arguye que las técnicas analíticas procedentes de la economía, la estadística y la investigación operativa se pueden usar objetivamente para averiguar ex ante o aprender ex post si las actividades públicas son valiosas o no. Las nuevas técnicas incluyen el análisis de políticas, la evaluación de programas, el análisis coste-efectividad y el análisis coste-beneficio. Los reformadores confiaron en que el uso de dichas técnicas podía insuflar hechos objetivos en las deliberaciones políticas sobre el grado en que las iniciativas propuestas eran viables y el grado en que los costes del esfuerzo gubernamental podían ser justificados por los beneficios sociales.

Se puede discutir ampliamente sobre el grado en que dichas técnicas han cumplido sus promesas, lo cual es mucho más de lo que podemos decir aquí. Desde la perspectiva de alguien que analiza el impacto global en el proceso de elaboración de las políticas, se puede afirmar que las técnicas no se utilizan de manera rutinaria ni son invariablemente útiles cuando se emplean. 'A pesar de ello, han conseguido cambiar el discurso político sobre programas públicos. Han incrementado el apetito del proceso político por argumentos basados en datos sobre el grado en que los programas consiguen los objetivos explicitados o sirven al interés general. 
Puede ser también importante que, como se ha mencionado anteriormente, las organizaciones públicas tengan una especie de capital basado en las habilidades para adaptarse y definir nuevos retos. En la medida en que dicho capital existe, la evaluación de sus resultados en tareas presentes no capturará el beneficio global para la sociedad. En cualquier caso, el uso de dichas técnicas ha sido más común para evaluar programas que para analizar el valor producido por organizaciones públicas.

El sector privado parece disfrutar de una medida más fiable del valor de su producción que el sector público. Los ingresos y beneficios de la venta de productos y servicios - es decir, el famoso margenproveen una medida directa del éxito de la empresa privada. Sin embargo, lo interesante de la rentabilidad es que mide lo que pasó en el pasado. Dicha medida se toma muy seriamente en el sector privado, en parte porque se puede utilizar para controlar y estimular a los gestores, pero también porque da a los gestores privados una ventaja para pensar en el futuro. De hecho, se ha recomendado a muchos gestores privados reducir su confianza en la planificación estratégica diseñada para producir predicciones más precisas sobre el futuro y, en su lugar, confiar en su habilidad para reaccionar rápidamente ante las condiciones cambiantes del mercado.

Consiguientemente, la lección del sector privado parece ser que es extremadamente valioso desarrollar información precisa sobre los resultados pasados en lugar de concentrar todos los esfuerzos en adivinar el futuro. En la medida en que esto sea cierto, se deduce que las agencias públicas se deben centrar más en la evaluación de programas que en el análisis de políticas. Mi impresión, sin embargo, es que hacen lo contrario. Esto es desafortunado, porque la atención incoherente dada a la evaluación de programas impide al sector público disponer del tipo de responsabilidad, incentivos y capacidad de reacción rápida de que dispone el sector privado poniendo atención en el margen.

Y, desde otra perspectiva, necesitamos analizar qué tipo de preferencias intentan satisfacer las actividades públicas. A menudo, las técnicas analíticas se presentan como si fueran siempre herramientas útiles para que el gobierno sepa si sus esfuerzos son valiosos o no. Entre ellas, el análisis coste-beneficio se presenta como la técnica superior, la más general y relacionada con el valor. La única razón para no utilizar dicha técnica es que pertenece a las más difíciles de manejar. Consiguientemente, la evaluación de programas y el análisis costeefectividad se presentan como subóptimos respecto al análisis costebeneficio. 
En resumen, tanto la evaluación de programas como el análisis costeefectividad define el valor público en relación con los objetivos definidos colectivamente que emergen del proceso de decisión colectiva, mientras que el análisis coste-beneficio define el valor a partir de las preferencias de los individuos sin referencia al proceso de decisión colectiva. La confianza del análisis coste-beneficio en las preferencias puramente individuales es, sin lugar a dudas, lo que lo hace conceptualmente superior a los ojos de los economistas del bienestar Pero, para aquellos que creen en la capacidad del proceso político respecto a establecer una aspiración colectivamente articulada, y que creen que ésta es la mejor guía para la acción pública, la evaluación de programas y el análisis coste-efectividad parecen ser mejores técnicas precisamente porque van más allá de las preferencias individuales, hacia los propósitos establecidos colectivamente.

Recientemente, los gestores públicos han elaborado una nueva teoría para aumentar el valor de sus actividades. Basándose en el sector privado, ponen el acento en el servicio al cliente y se comprometen a valorar sus esfuerzos en la satisfacción de los usuarios y en la instauración de procesos de calidad. Habiendo convertido a la calidad en una especie de panacea que viene a solucionar todos los problemas que aquejan a la Administración Pública. Nada más lejos de la realidad, y quien esto afirma tiene la suficiente experiencia para atestiguarlo. La calidad no soluciona nada, únicamente refuerza y proporciona coherencia a los procesos que previamente estén establecidos. La calidad, sin embargo, sí que evidencia las malas políticas de gestión utilizadas en las Administraciones Públicas, por lo que resulta paradójico que la utilicemos como argumento favorecedor de las políticas privatizadoras. Se exige calidad en los contratos, a la empresa contratante, de aquellas prácticas en las que a la Administración le ha sido imposible efectuar ningún tipo de parametrización. Es, cuanto menos, una de las tantas paradojas de las que pervive la Administración Pública. No obstante, deseamos brindar unas cuantas reflexiones en torno a las grandes posibilidades que la calidad ofrece, tanto a la Administración Pública como a las empresas privadas o de iniciativa social que presten servicios sociales para la Administración Pública.

\section{LA CALIDAD DE LOS SERVICIOS SOCIALES ENTRE LO PÚBLICO Y LO PRIVADO.}

La preocupación por la calidad de los servicios sociales no es, obviamente, nada nuevo, aunque sí es escasa la bibliografía en la que apoyarnos (Medina, 1996;1997). Pese a ello, actualmente, parece existir 
un repentino y gran interés explícito por la cuestión de la calidad, lo que nos lleva a plantearnos algunas cuestiones: ¿por qué se ha intensificado este énfasis sobre la calidad?, ¿por una simple moda?, ¿o se trata de una forma más o menos encubierta de justificar las nuevas teorías del sistema de mercado, en la prestación de servicios sociales vinculados a la paulatina desaparición del Estado del Bienestar?. Pensamos, sin embargo, que el verdadero inicio de los estudios de calidad que se ha producido, tanto en otros países de nuestro entorno como en el nuestro, ha estado y está, en gran medida, unido a aspectos económicos, concretamente, a la restricción económica y a la búsqueda de la rentabilidad de los escasos recursos estatales. Pero también existen otras voces que vinculan el auge de la calidad, exclusivamente ligado a la rentabilidad, esté situado el elemento productor en la empresa pública o en la privada.

En este sentido, desde nuestra perspectiva, creemos que hay que tener en cuenta que las prestaciones que se realizan en el marco del Sistema Público de Servicios Sociales se consideran un derecho y deben proporcionarse independientemente de su mayor o menor rentabilidad. Sin que tengamos que abrir aquí un debate sobre lo que vamos a entender por rentabilidad, salvo que pongamos en el fiel de la balanza la rentabilidad de los procesos y la rentabilidad de los servicios que se prestan. Sin embargo, y esto sí es bueno, se debe reflexionar y cuestionar el discurso que sitúa la productividad por delante de otras cuestiones, alejándola de términos como eficacia y eficiencia, reduciendo las prestaciones sociales a meros listados de actividades o a específicas secuencias de datos, haciendo real lo que Kaplan y Merton (1992) denunciaban refiriéndose a las asociaciones, pretendidamente no lucrativas que prestan servicios sociales, señalando que la evaluación de resultados, aquella que demuestra los efectos producidos en los usuarios, es algo más que una memoria con datos y números y deben demostrar cómo la satisfacción del usuario, unida a la mejora de los procesos internos, las actividades de innovación organizativa y el interés por los clientes internos, serán los auténticos responsables de que podamos hablar de calidad que en definitiva debería ser la meta de una organización que se considere con perspectiva de futuro (Medina, 1998).

Es preciso, sin embargo, que seamos conscientes, y creemos que ya ha quedado explicitado la existencia de una fuerte tendencia a la gestión privada como un claro exponente de aumento de la competitividad y esta orientación actual hacia la calidad se ve acelerada, según López (1994), por el marketing; por las empresas que están orientando cada vez más su actividad y su gestión hacia la calidad y por la progresiva apertura de los sistemas sociales y económicos, que conlle- 
va un aumento de la competitividad y hace que se incluyan criterios de eficiencia económica en la realización de cualquier actividad. Para este autor, el sector público es pesado y cerrado. Además, estamos en tiempos de descrédito del Estado como administrador. Todo ello reclama la privatización, más que eso, se trata de implantar en el ámbito de lo público los procedimientos que se han revelado eficientes en la gestión de lo privado (aunque en la práctica no resulta nada fácil).

La calidad apenas forma parte de la cultura organizativa de los servicios sociales en España, considerados tanto, desde su perspectiva de comunitarios como de especializados, y así podemos comprobarlo al manejar la escasa bibliografía existente al respecto.

A modo de ejemplo, señalaremos algunas de las publicaciones que tímidamente van apareciendo y conformando un espacio que deseamos siga creciendo por el bien de los servicios sociales. Desde un posición global, aborda Porcel (1997) el difícil entorno de la calidad total en el trabajo social y su aplicación a diferentes ámbitos; la gestión de calidad en los servicios sociales es objeto de reflexión en Sacanell (1996; 1998) y, de forma práctica, en relación a la aportación de los círculos de calidad, Herrera (1996) presenta una experiencia de implantación en la administración local, en el área de servicios sociales del Ayuntamiento de Jaén.

La calidad asistencial de los servicios sociales, tal y como defendemos en este artículo, apenas tiene reflejo en las publicaciones revisadas (Fernández, Pérez, Medina et al., 1995; Medina, 1998) en el que se analiza la calidad del servicio de ayuda a domicilio; la evaluación de la calidad de los servicios sociales contemplada de forma integral (Medina, 1995); la garantía de calidad en la aplicación práctica de la evaluación de programas (Medina, 1996) o el marco teórico para la evaluación de la calidad asistencial en servicios sociales (Medina, 1996; 1997).

Sin embargo, en donde más se ha desarrollado el interés por la calidad ha sido en los servicios sociales especializados: la atención al cliente y su relación con la calidad del servicio (Elorriaga et al., 1997), la importancia de los recursos humanos y la calidad en las residencias de personas con retraso mental (Forteza, 1996); experiencias de gestión de calidad total (Aguiriano, 1998), la consideración de la calidad organizativa y su importancia en las instituciones para discapacitados psíquicos (Lacasta, 1998); en el amplio campo de las toxicomanías (SEIT, 1993); la evaluación de la calidad del servicio de teleasistencia (Rodríguez, 1996; IMSERSO, 1997); la evaluación de la calidad de Ios servicios del programa de termalismo social (INSERSO, 1992); la evaluación de la calidad en los centros residenciales y de acogida para menores (Fernández del Valle, 1998); la asistencia de la calidad de las 
personas mayores: desde una perspectiva general (Ruipérez, 1988), en las residencias (Suárez, Cifuentes y Merchán, 1992), en la elaboración de protocolos de evaluación (Medina, 1993b); en los centros de integración laboral (Fernández, 1996), la elaboración de estándares de calidad para la integración laboral de personas con discapacidad (MTAS y Fernández, 1997).

Fuera de nuestras fronteras, si bien es verdad que nos llevan algunos años de ventaja en relación a las propuestas metodológicas de evaluación de calidad, cuando se revisa la bibliografía, la distancia ya no es tan larga. Una reciente revisión (Alaszewski y Manyhorpe, 1993), actualizada posteriormente en 1997, señala que el nivel de producción sobre la calidad en el ámbito de los servicios sociales deja mucho que desear por su falta de cientificidad y abuso de metodologías puramente cualitativas. Algunas publicaciones señalan la importancia que para el futuro de los servicios sociales tiene el que se desarrollen evaluaciones de la calidad de las intervenciones (Greenley, Greeberg y Brown, 1997). Aprovechando los planteamientos reformistas que se están imponiendo en Estados Unidos, la calidad ha sido impulsada como requisito de puesta en marcha de programas de actuación y, al respecto, reflexionan (Stoker, Wilson-Gentry, Thomas y Clark, 1997); destacar la importancia de la calidad en gestión de calidad de los recursos humanos para el desarrollo de políticas de bienestar social (Wilding, 1994); las orientaciones respecto a la voz y a la importancia que debe tener el usuario o cliente de los servicios sociales y el papel que debe jugar en el proceso de calidad (Moore y Kelly, 1996); o la importancia de la medida de la satisfacción (Soliman y Poulin, 1997); la utilización de tecnologías o herramientas determinadas del ámbito de la calidad (Auslander, 1996); la calidad total en el campo de los servicios sociales, al menos en el contexto americano, tiene un determinado interés (Martin, 1993; Raynos, Gelsthorpe y Tisi, 1995), unido a la tecnología del TQM (Storr, 1996) y desde una perspectiva más asistencial, en relación al tratamiento de los ancianos y enfermos de larga duración que cada vez se aproximan más al campo de los servicios sociales, alejándose de lo sanitario, encontramos la aportación de Lyosn, La Valle y Grimwood (1995).

Sobre la función calidad, todos somos conscientes que es la traducción operacional, en herramientas y métodos de gestión, de la necesidad que tienen las empresas, para ser competitivas, de ofrecer a sus clientes los productos que satisfagan sus necesidades, cubran sus expectativas y respeten su estructura de preferencias. Sin embargo, siendo esto cierto en el ámbito empresarial, la ausencia de una referencia sistemática a un cuerpo teórico propio ha conducido, en el contex to de los servicios sociales, según nuestra experiencia, a conceptuar la cali- 
dad, desde un perspectiva muy reducida, como el conjunto de técnicas y actividades de carácter operativo destinado a comprobar que el servicio prestado cumple los requisitos relativos a la calidad y a actuar sobre las desviaciones. Esta confusión respecto a la calidad está muy extendida en organizaciones prestadoras de servicios sociales, ya que el fin de la calidad no ha sido comprendido ni aceptado, y únicamente se ha perseguido la certificación, la obtención de un diploma que avale los procesos y procedimientos.

En este artículo nos referimos a los servicios en los que las administraciones públicas adquieren un papel determinante en la decisión de suministrarlos, estableciendo la cobertura y condiciones bajo las cuales se ha de producir la prestación, así como su sistema de financiación: los servicios sociales, y a las prestaciones que desarrollan a través, por ejemplo, de los centros de servicios sociales. Indicando que uno de los problemas y, a su vez, beneficios de los servicios sociales es que se articulan a partir de los ayuntamientos, y esto tiene de positivo la cercanía y la proximidad del ciudadano a la hora del desempeño de las prestaciones, pero el inconveniente es de tipo presupuestario, ya que, en muchas ocasiones, los ayuntamientos realizan las prestaciones mediante convenio con los entes autonómicos que necesitan una formalización económica. También las estructuras municipales, en ocasiones están ancladas, no han desarrollado proyectos de modernización, desoyendo los argumentos que cada vez se van instalando en la Administración Pública española (Ayuntamiento de Murcia, 1993; MAP, 1996; López y Gadea, 1995 y VI Congreso Nacional de la Calidad, 1996). Pero también hemos de reconocer que a lo largo de la última década se ha producido un progresivo cambio en la mentalidad, tanto de los políticos y gestores como de los ciudadanos, con respecto a sus expectativas, frente a los servicios públicos, de forma que, mientras anteriormente apenas existían reivindicaciones acerca del funcionamiento de los servicios colectivos, se ha pasado a una situación en la que cada vez es más patente la exigencia ciudadana de que se gestionen los servicios públicos con criterios de calidad. Por eso, tanto podríamos hablar de calidad de gestión como de gestión de calidad.

\subsection{Gestión de calidad}

Los fundamentos de la calidad son, en definitiva, el conjunto de principios, métodos y estrategias que intentan movilizar a toda la organización con el propósito de obtener la satisfacción del usuario al menor coste posible. La calidad es un sistema de pensamiento donde la excelencia rige las decisiones y actividades de todos y cada uno de 
los integrantes de la organización y en todos los niveles, incluida la Dirección, que debe formular la política de calidad y constituirse en impulsora del cambio y garante del sistema de calidad.

Los fundamentos de la gestión de la calidad, adaptados del mundo empresarial al ámbito de la Administración Pública, podrían resumirse en:

- El objetivo es la rentabilidad y la mejora continua.

- Pretende ayudar a satisfacer las necesidades del usuario.

- Los recursos humanos son su elemento más importante.

- Es preciso el trabajo en equipo para conseguirla.

- La comunicación, la información y la participación a todos los niveles son elementos imprescindibles.

- Se busca la disminución de costes mediante la prevención de las anomalías y fallos.

- Implica fijar objetivos de mejora permanente y la realización de un seguimiento periódico de resultados.

Los servicios sociales -entendidos en un sentido genérico-constituyen un tipo singular de organización que, a la alta especificidad propia del ámbito de la intervención social, suma las señas de identidad características de la función pública; de modo que aplicar a este sector los objetivos antes referidos es considerado, con frecuencia, por sus protagonistas, como inoportuno. Sin embargo, existe en la actualidad sobrada evidencia empírica como para reconocer que el modelo de gestión de los Centros públicos que opera en nuestro país, sean éstos del ámbito que sean, está sumido en una crisis cuya influencia sobre la concepción de gestión de calidad, aunque reclamada y conocida por los expertos su inexistencia, pasa a menudo inadvertida para la sociedad, entre otras razones, por la peculiar naturaleza del servicio que se proporciona -buena parte de cuyos efectos se advierten, principalmente, en el medio y largo plazo-y por la escasa referencia a los resultados - a la medida de la eficiencia- y a la comparación, con fines evaluativos, que dicho sector presenta.

Uno de los elementos definitorios de la eficiencia, junto a la calidad, es la medida de la satisfacción del usuario. Por esa razón, aquí nos queremos detener en este apartado, aunque no con la intensidad que se merece, sí con unas breves pinceladas que perfilen este tema para el futuro empírico tan necesario en los servicios sociales.

\subsection{Satisfacción del usuario}

La satisfacción ciudadana por la calidad de un servicio está relacionada con el conjunto de propiedades que debe tener ese servicio para atender, en primer lugar, las necesidades (explícitas e implícitas) 
de las personas a las cuales va destinado. Pero esto, aunque sea necesario, no es suficiente. Porque la satisfacción va ligada también a la percepción que el ciudadano tiene de cómo se presta el servicio y a la expectativa que tenía respecto al servicio esperado. Aunque, esta situación nos lleva a un lugar conflictivo como es la concepción del ciudadano como cliente de los servicios y esto sí significa un enorme cambio en las bases políticas de las administraciones y especialmente la municipal. Como bien indica García Roca (1992, pág. 31), el estado no se justifica por el respeto a las leyes, la división de poderes y los procedimientos de la toma de decisiones, sino por las prestaciones del estado que exigen los ciudadanos.

Corresponde que nos preguntemos en este momento. ¿Qué significa satisfacción del usuario?. Sobre este criterio se fundamenta gran parte de la filosofía de las organizaciones que tienen o muestran algún interés por la calidad. Es tan importante que se convierte en el núcleo de toda la actividad de la organización. Las instituciones que deciden trabajar con criterios de calidad utilizando alguno de los modelos existentes, planifican, generan procesos, diagnostican, se autoevalúan, toman decisiones, producen servicios, crean estructuras y mecanismos de comunicación para y en función del cliente. Por esta razón, es de gran importancia que podamos definir de forma operativa lo que significa satisfacción del usuario. Siguiendo algunas de las reflexiones de Álvarez (1998), destacamos los dos puntos que tienen gran utilidad para nuestro argumento: a) Identificar los factores críticos de éxito que constituyen el núcleo de las expectativas del usuario. Para ello es fundamental conocer (escuchar) las necesidades y demandas de los usuarios, y solicitar la opinión del usuario sobre la satisfacción del servicio que le estamos ofreciendo o le hemos ofrecido; $y$ b) destacar la importancia del personal de primera línea (trabajador social, psicólogo, educador), que son las personas claves en el proceso interventivo y, de manera especial, cuando surge una situación de conflicto o de insatisfacción con el usuario. Para ello, es necesario conocer el mayor número de aspectos de estos profesionales con el fin de calibrar el papel que auténticamente desempeñan en la prestación de los servicios. Por lo tanto, el objetivo de cualquier estudio que desee determinar la percepción de calidad de los usuarios de un centro de servicios sociales deberá contemplar, además de los ámbitos ya considerados de cultura organizacional y clima, aspectos y variables actitudinales como el nivel de satisfacción laboral, burnout y compromiso organizacional que presentan los profesionales, puesto que son los de mayor contacto con los usuarios y, como consecuencia, responsables de influir sobre la percepción de calidad asistencial que puedan tener los usuarios. 
Los dos grandes ejes de las organizaciones prestadoras de servicios públicos, tanto en el mundo de la empresa privada como en el sector público, son, sin duda, los clientes externos (receptores del servicio), clientes internos y proveedores, los que ejecutan y llevan a cabo el servicio. Sobre el primer eje ya hemos avanzado lo que la calidad asistencial contempla como importante: verificar el nivel de satisfacción; el segundo, consistiría en analizar el amplio espectro de posibilidades que los recursos humanos de las entidades prestadoras de servicios sociales tienen. Pero este es el problema, poco, o muy poco, existe sobre la contextualización profesional de los trabajadores de servicios sociales y, si existe alguna bibliografía (Luque, 1988; Rodríguez, 1996; Peiró y Medina, 1996, Torres Gómez et al., 1996), no está específicamente dirigida a ningún ámbito concreto sino estructurada de forma general. La bibliografía consultada al respecto, aunque relativa a campos próximos, como, por ejemplo, el sanitario, especialmente el de atención primaria, nos han permitido establecer algunas consideraciones sobre las actitudes hacia el trabajo, lo que también es fundamental para comprender en toda su dimensión las posibilidades de los centros de servicios sociales. Así, la satisfacción laboral, entendida como una actitud favorable, tanto hacia el trabajo en general, como hacia aspectos específicos de éste, suele aparecer relacionada de modo positivo con el compromiso organizacional y de modo negativo con el burnout. Y todas estas variables son esenciales para comprender la calidad asistencial.

\subsection{Medida de la satisfacción del usuario en servicios sociales}

La satisfacción de los usuarios con la atención recibida es concebida como una medida de control de calidad (Calero y Calero, 1991) por lo que su estudio y valoración es importante para la gestión y el trabajo de los profesionales de los servicios de salud y de servicios sociales en su conjunto, con la perspectiva de conseguir una mejor adaptación a las necesidades y deseos de los usuarios del sistema.

Autores como Howell (1976), Fleming (1981), Vuori (1982), Suñol (1987), Ware (1988), Medina (1994), Saturno (1997) y otros, además de organizaciones como la OMS y la Unesco, han señalado la importancia y pertinencia de introducir la satisfacción de los usuarios con los servicios como parte y complemento de otras actividades de control de calidad.

Desde nuestra perspectiva, compartida con Ana Delgado (1992), el objetivo principal de conocer la satisfacción de los usuarios es obtener información para llevar a acabo una intervención que permita mejorar las actuaciones profesionales. 
La satisfacción del usuario en relación al resultado de la asistencia, es decir, la opinión del mismo acerca de si el resultado obtenido era el mejor posible, no solía estar incluida en las medidas de satisfacción (Pallarés y García, 1996). En las evaluaciones de calidad asistencial sanitaria, tales juicios los realizan normalmente los profesionales, porque no es probable que los pacientes tengan los conocimientos técnicos que se necesitan para emitir un juicio sobre los máximos beneficios alcanzables por la asistencia sanitaria, esto ha cambiado lo suficiente, incluso con la creación de organizaciones de consumidores que asesoran a los pacientes, y otro tipo de organizaciones de defensa del consumidor, que reclaman la participación del paciente en todo lo que tiene que ver con el proceso asistencial (Martínez del Olmo, 1994; Gómez y Saturno, 1997); sin embargo, los usuarios del sistema de servicios sociales sí tienen criterio en muchas ocasiones, incluso los conocimientos necesarios para mantener una opinión definida (Medina, 1994; 1996a; 1997b).

Dos conceptos esenciales sobre la satisfacción del usuario surgen de la investigación de Ware: Los mecanismos de acceso, que incluyen los esfuerzos para buscar, concertar y recibir asistencia, y la actuación del profesional, que supone emitir juicios de valor sobre la calidad de la interacción con el profesional. Aparentemente, los entrevistados no distinguen entre la competencia técnica de los profesionales y su capacidad de relación interpersonal. Estos dos conceptos principales se corresponden con los conceptos de calidad de la asistencia, de accesibilidad y aceptabilidad. Dentro del concepto acceso, los usuarios diferencian una serie de subconceptos que, tomados de distintas disciplinas y debidamente adaptados, podemos aplicarlos a los servicios sociales, por ejemplo, en relación a los horarios de visita (Escalera et al., 1991) y ubicación de un centro (Mackesy, 1993); tiempo de demora para una citación (Gómez Calcerrada et al., 1996), la cita previa y los problemas de accesibilidad telefónica (Duarte y Godoy, 1997); accesibilidad telefónica (Pascual, et al., 1994), tiempo de espera en la consulta (Villanueva López et al., 1997), horarios y forma de pago; diferencias entre público y privado (Prieto, López y March, 1994), dificultades de la cita previa en general (Alastrué Loscos et al., 1992). También nos podemos encontrar con diversas consideraciones de accesibilidad, una de las más llamativas es la atención en los servicios de urgencias (Percerisa et al., 1997; Allende, Pacheco y Jürschik, 1998) son algunos de los ámbitos, como ejemplos específicos, para el desarrollo de encuestas de satisfacción.

Dentro de la actuación del profesional, los usuarios distinguen subconceptos tales como acogida (Maldonado y March, 1994; Madera et al., 1995), perfección, prudencia, recogida y facilitación de infor- 
mación (Estévez et al., 1995; Sánchez, Saturno et al., 1997; De la Calle Santisuste et al., 1997), atención a la asistencia preventiva (Espinosa et al., 1994), respeto (Gil Cebrián et al., 1993), preocupación (Mira, Valls, Velasco y Serra, 1997), amistad y cortesía (Doyle y Ware, 1977) y en relación con las características del profesional (Delgado et al., 1997).

Uno de los aspectos que cada vez se tiene en cuenta en la accesibilidad es el uso del teléfono que ha sido estudiado tanto desde la perspectiva sanitaria como teléfono de atención al paciente para el aumento de la calidad asistencial (Sánchez, Ortiz y Pineda, 1994), como en la cita previa (Angel y Vázquez, 1994); o en los teléfonos de urgencia (Curieses, Bermejo y Alvarez, 1991) y también con respecto a la cita previa en los servicios sociales (Duarte y Godoy, 1997).

\section{A MODO DE CONCLUSIÓN}

En España la privatización o el debate en torno a lo público-privado adquiere una serie de consecuencias territoriales muchas veces ignoradas. En España no existe el Estado del Bienestar, sino las Comunidades Autónomas del Bienestar y las Corporaciones Locales del Bienestar. Esta afirmación únicamente pretende señalar que el proceso de los servicios sociales está en diferentes manos políticas y administrativas que no siempre coinciden en sus planteamientos ni en sus intereses. Lo que para una Administración puede ser contratación externa, otra puede entenderlo como privatización, o aquella que ponga en marcha un sistema de gestión de calidad la otra puede entenderla como un proceso de control. La ausencia de una auténtico marco integrador de los servicios sociales hará que resulte difícil, aunque no imposible, la articulación de mecanismos más allá del denostado Plan Concertado que, a la postre, no es nada más que un mecanismo administrativo.

Las tendencias modemizadoras en los servicios sociales, y, en general, en los servicios públicos, van a girar, están girando ya, entorno a la privatización, unas veces clara y otras encubierta en modalidades variadas y entendiendo ésta en un sentido amplio, que va desde la importación de técnicas del sector privado hasta la prestación directa de determinados servicios por dicho sector. Ello no quiere decir que la salida a la situación actual sea la privatización, sino que ésta va a ser tomada como referencia, en su sentido positivo o negativo, en la prestación de los servicios sociales. Dicho de otra forma, la eventual incorporación al catálogo de servicios sociales públicos de una nueva prestación exigirá una reflexión sobre quién la va a realizar y cómo. 
De igual modo, la reconsideración del actual catálogo, a la luz de las disponibilidades presupuestarias, exigirá una reflexión análoga.

La cuestión de lo público y lo privado todavía no se ha planteado con el rigor de un debate científico, ni siquiera como debate político, es claro que los fenómenos privatizadores van a ser una constante inmediata en nuestro país, como lo están siendo en el resto de la Unión Europea. Con ello no nos referimos únicamente a los debates electorales que se avecinan, sino a la necesidad de plantear alternativas organizativas al insuficiente nivel de los servicios sociales por parte de los más directamente implicados que, sin duda, serán los empleados públicos.

Los fenómenos privatizadores no pueden olvidar el papel integrador que cumplen las prestaciones sociales. Por ello, se requiere un elaborado diseño de los límites entre lo público y lo privado logrado mediante el máximo consenso político, el estudio caso a caso de cada sector de la actividad susceptible de ser privatizado y la participación activa en el debate de los actores sociales. Una vez realizado el proceso privatizador, debe asegurarse firmemente el cumplimiento de los fines públicos que han sido delegados a una determinada entidad no pública. Esto significa el ejercicio de funciones de control político eficaces, ya que privatización no puede significar renuncia.

Una de las cuestiones de mayor debate ante los sistemas de gestión en la Administración ha sido la creencia de que la gestión indirecta reducía costes. En esta línea, se ha planteado la contratación como una forma sustitutoria de los convenios, donde hay una aportación de dos partes para llevar adelante un programa. La contratación externa no exime a la Administración de ser responsable de sus costes, ni ha de servir para utilizar el voluntariado de las asociaciones para los servicios que han de ser remunerados. Todo lo cual no quiere decir que determinados costes de estructura que se crean en la Administración al iniciar un servicio no sean menores o menos costosos en el seno de las estructuras privadas, pero la determinación de este tema con exactitud todavía está pendiente de estudio.

También debemos tener presente a la hora de enjuiciar los mecanismos privatizadores las dificultades para contratar personal derivadas del congelamiento del crecimiento del Capítulo 1 de los Presupuestos. De esta necesidad se derivaron contratos de prestación de servicios que en realidad fueron contrataciones laborales encubiertas donde al contratista sólo se le asignaba el papel de gestoría administrativa.

Igualmente los problemas de gestión administrativa también han sido la causa de muchos contratos de servicios, o bien por ser la única vía posible para determinados programas en específicos momentos, o 
bien como capitulación frente a las dificultades para realizar una reforma administrativa en profundidad.

La aparición y proliferación de entidades prestadoras de servicios puede provocar, y de hecho ya ocurre en torno a determinadas entidades, la formación de lobbys para defender sus intereses. Esto, que de hecho es una realidad en otros ámbitos, puede tener unas vertientes positivas, en el sentido de ayudar a la consolidación de estos sectores, pero puede provocar también situaciones de presión, más derivadas de los propios intereses de las entidades que de las necesidades sociales a que han de dar respuesta las Administraciones Públicas.

Desde un posicionamiento más positivo, es necesario que la Administración tome conciencia de que, si quiere evitar el permanente acoso crítico a la que le somete la iniciativa privada debido a sus procedimientos, erradique hábitos operativos malos que empañan la actuación administrativa, entre ellos, el vicio reglamentista y funcionarial, lo que algunos autores ya empiezan a denominar papelismo y tramitomanía. Es preciso racionalizar los procesos y simplificar las actuaciones, y esto es más urgente en el ámbito de los servicios sociales si de verdad existe un interés de aproximar las prestaciones sociales a los ciudadanos. El descrédito de la Administración es preciso combatirlo con eficacia. Es necesario fortalecer los mecanismos formativos elaborando buenos diseños que analicen las necesidades y luego dirijan sus intereses a fortalecer los conocimientos y las herramientas de los empleados públicos, tanto para dar coherencia a su trabajo como para hacer frente a las posiciones de análisis y control que los mecanismos de privatización o de contratación externa o de convenios les exige.

La calidad, tanto desde la perspectiva de su evaluación, como desde su implantación como herramienta útil de gestión, debe ser contemplada como inherente a los procesos de trabajo que proporciona rentabilidad, tras apoyarse en un trabajo bien hecho, sin defectos o, al menos, con un mecanismo capaz de detectar los fallos y eliminarlos. La calidad no es patrimonio de la empresa privada que se importa a la empresa pública. La calidad es patrimonio de aquellas organizaciones que quieran trabajar con un nivel de valor añadido que aumente la confianza de los usuarios en el servicio que se presta y de ésto los empleados públicos de servicios sociales entienden bastante más que otros. Y la calidad debe ir unida a una cultura que consiga instalar la satisfacción del usuario como componente imprescindible del sistema, sea la empresa privada o la pública la que efectúe la prestación social comprometida.

Por último, es preciso terminar con una llamada a la creación de un comportamiento del que estamos huérfanos en servicios sociales: la investigación. Tanto el sector público como el sector privado pueden 
ser observados como elementos diferenciados -o sea, como dos compartimentos estancos-, o bien como dos valores extremos de un continuum de categorías con situaciones intermedias; sin embargo, es importante que se pueda determinar cuáles son los ámbitos de gestión que definen lo que es público y lo que es privado: ¿Qué servicios y prestaciones son o tienen que ser exclusivos? ¿Cuáles pueden ser prestados por ambos? ¿Qué funciones son exclusivas de uno o de otro? ¿Qué tipologías y características de público y privado? ¿Qué interrelaciones se dan? Y estas preguntas deben responderse de forma empírica.

\section{BIBLIOGRAFÍA}

AGUIRIANO BEITIA, A. (1997): Experiencia práctica en la gestión para la calidad total. Siglo Cero, 29, 1, 15-22.

ALASTRÚE, J. et al. (1992): Evaluación del programa de cita previa en atención primaria a través de una encuesta de opinión de usuarios. Atención Primaria, 9, 6, 299- 304.

ALASZEWSKI, A. y MANTHORPE, J. (1993): Quality and the Welfare Services: A literature Review. British Journal Social Work, 23, 653-665.

ALLENDE, P.; PACHECO, A. y JÜRSCHIK, P. (1998): Servicio de urgencias de un hospital. Perspectiva de los acompañantes del usuario. Todo Hospital, 145, 203-206.

ALVARADO, E. (Coord.) (1998): Retos del Estado del Bienestar en España a finales de los noventa. Madrid. Tecnos.

ALVAREZ, M. (1998): El liderazgo de la calidad total. Madrid. Editorial Escuela Española.

ASCOLI, U. (1996): I welfare mix in Europa. Assistenza Sociale, 1, 2134.

AUSLANDER, G.K. (1996): Outcome Evaluation in Host Organizations: A Research Agenda. Administration in Social Work, 20, 2, 15-27.

Ayuntamiento de Murcia (1993): Jornadas sobre modernización de la Administración Pública Local. Murcia.

BARINAGA, R. (1994): Opción política en la redefinición del Estado del Bienestar. Zerbitzuan, 25, 37- 39.

BEESLEY, M. (1993): Privatisation: Principles, Problems and Priorities. Lloyd Bank Review, 149, 1-20.

CAINZOS, J.J. (1991): Los componentes público-privado del Estado de Bienestar: Una perspectiva constitucional. En G. Rodríguez Cabrero: Estado, privatización y bienestar. Pág. 47-95. 
CALERO, M.J. y CALERO, M.D. (1991): Control de calidad asistencial. Revista ROL de Enfermería, 154, 33-40.

Círculo de Empresarios (1997): El Estado de bienestar a examen: un reto par el sector privado. Madrid.

Congreso Nacional de la Calidad (VI) (1995): Calidad por y para el hombre. Madrid. Ediciones Gestión 2000, S.A.

CREE, V.E. (1995): From Public Streets to Private Lives: The Changing Task of Social Work. Avebury. Aldershot.

CURIESES, A.; BERMEJO, R. y ALVAREZ, J.A. (1991): Encuesta de satisfacción de los usuarios con el teléfono 061 de urgencias sanitarias en la Comunidad de Madrid. En VI Jornadas de Salud Pública y Administración Sanitaria, pág. 203-204. Granada. Escuela Andaluza de Salud.

DE LA CALLE, A.; MORENO, E.; DE ALBA, V.; GARCIA, M.J.; FLORES, M.C. y FERNÁNDEZX-MIRANDA, C. (1997): Calidad de información, comunicación y grado de comprensión en 590 pacientes quirúrgicos y familia. En XV Congreso de la Sociedad Española de Calidad Asistencial. Revista de Calidad Asistencial, 12, 338.

DELGADO, A.; HAZAÑA, M.P.; HERRERO, C.; MARÍN, I. y REYES, M.C. (1994): El perfil del médico y la calidad asistencial. En IX Jornadas de Salud Pública y Administración Sanitaria, pág. 48. Granada. Escuela Andaluza de Salud Pública.

DELGADO, A.; MARÍN, I., REYES, M.C.; HERRERO, C.; HAZAÑA, M.P. y BAILÓN, E. (1997): La calidad de la atención en relación con características del médico. En XV Congreso de la Sociedad Española de Calidad Asistencial. Revista de Calidad Asistencial, 12, 401-405.

DONAHUE, J.D. (1991): La decisión de privatizar, fines públicos y medios privados. Madrid. Paidos.

DONATI, P. (1996): Le politiche sociali in Italia oltre la crisi del welfare state: verso quali configurazioni. La Rivista di Servizio Sociale, 1, 3.

DONATI, P. (1997): La crisis del estado Social y la emergencia del tercer sector: hacia una nueva configuración relacional. Revista del Ministerio de Trabajo y Asuntos Sociales, 5, 15-25.

DUARTE, A. y GODOY, S. (1997): La cita previa en un Centro de Servicios Sociales. En M.E. Medina, C. García y A. Romero. (Comps.): La psicología como profesión ( $2^{\circ}$ vol.). Universidad de Murcia y COP.

ELORRIAGA, J.; FERRER, R.; FUENTETAJA, A.; GARROFE, R.; REY, F. y RUEDA, P. (1997): Atención al cliente y calidad del servicio. Siglo Cero, $28,1,19-44$.

ESCALERA, M.; PÉREZ, R.; GONZÁLEZ, B.; MOYANO, G. y VARGAS, A. (1991). Análisis de la satisfacción del usuario con el horario actual de visitas en el Hospital regional de Málaga. En VI Jornadas de Salud Públi- 
ca y Administración Sanitaria, pág. 205. Granada. Escuela Andaluza de Salud Pública.

ESPINOSA, J.M.; ORTEGA, I.; HERNÁNDEZ, J.M.; MUÑOZ, F. y CARRASCO, A. (1994): Opinan nuestros clientes: ¿Hay que potenciar una nueva forma de atención en consulta médica?. En IX Jornadas de Salud Pública y Administración Sanitaria, pág. 108. Granada. Escuela Andaluza de Salud Pública.

ESPINOSA DE LOS MONTEROS, C. (1997): Crisis y reforma del Estado de bienestar. En Círculo de Empresarios (1997), pág. 101-119.

ESTÉVEZ, J.; HERNANDO, A.; ZABALA, E.; GONZÁLEZ, M. y VÁZQUEZ, M. (1995): Planificación e integración de los profesionales en la mejora de la información. En XIII Congreso de la Sociedad Española de Calidad Asistencial. Revista de Calidad Asistencial, 12.

ETXEZARRETA, J.C. (1995): La privatización en la Administración Local. Barcelona. Bayer Hermanos, S.A.

FERNÁNDEZ, S. (1996): Evaluación de programas y centros de integración laboral. Guía de estándares de calidad profesional. En II Escuela de Verano de Servicios Sociales de Almuñecar. (Documento fotocopiado). Diputación de Granada.

FERNÁNDEZ DEL VALLE, J. (1998): Los estándares de calidad de los servicios sociales a la infancia y familia. En $V$ Congreso Estatal de Intervención Social (en prensa). Madrid: Colegio Oficial de Psicólogos.

FERNÁNDEZ. J; PÉREZ, R. y MEDINA, M.E. (1995): Análisis de calidad del servivio de Ayuda a Domicilio. En I Jornadas de Trabajo Social de la Región de Murcia. Colegio Oficial de Diplomados en Trabajo Social, pág. 55-71.

FLEMING, G.V. (1981): Hospital structure and consumer satisfaction. Health. Sev. Res., 16, 43-63.

FORTEZA, S.; RAMÓN, M. y MOREY, E. (1996): Evaluación de las interacciones sociales entre los profesionales de atención directa y los usuarios de una residencia de personas con retraso mental. Siglo Cero, 27,5, 33-39.

GARCÍA ROCA, J. (1992): Público y privado en la acción social. Madrid. Editorial Popular.

GIDDENS, A. (1994): Consecuencias de la modernidad. Madrid. Alianza.

GIL, J.; RODRÍGUEZ, J.G.; DÍAZ-ALERSI, R.; MARTÍNEZ, P.; HUERTOS, M.J. y RUIZ, M.A. (1993): La comunicación con el usuario y sus familiares en una Unidad de Medicina Intensiva. Interés de la encuesta post-alta. Medicina Intensiva, 18, 2, 55-60.

GÓMEZ- CALCERRADA, D.; PÉREZ, D. y MARSET, P. (1996). La cita previa, perfil del consultante y accesibilidad. Atención Primaria, 17, 4, 288-291. 
GÓMEZ, P. y SATURNO, P.J. (1997): La calidad en atención primaria de salud según sus diferentes protagonistas. I Congreso Regional de Calidad Asistencial. Murcia.

GONZÁLEZ M.J. (1996): ¿A dónde va el sector público? Del Estado de Bienestar al bienestar con menos estado. Madrid: Instituto de Estudios y Anális Económicos.

GOODMAN, J.B. (1994): Privatización del sector público: ¿acierto o disparate?. Deusto Bussiness Review.

GREENLEY, J.R.; GREENBERG, J.S. y BROWN, R. (1997): Meauring Quality of Life: A new and practical Survey Instrument. Social Work, 42, 3, 244-254.

HANKE, S. (1991): Privatización del sector público. Revista de Estudios del Instituto de Estudios Económicos, 1, 137-171.

HEMMING, R. y MANSOOR, A.M. (1994): La privatización y las empresas públicas. Revista de Hacienda Pública, 128, 231-235.

HERRERA GARRIDO, F. (1996): Círculos de calidad. Proceso de implantación en la Administración Local. IV Jornadas de Intervención Social. Tomo 2, pág. 1235-1245. Madrid: Colegio oficial de Psicólogos de Madrid/ INSERSO.

HOWELL, J.R. (1976): Aproposed method for self-assessment in primary care organizations. Journal Commun Health, 4, 56-57.

HUNTIGTON, S.P. (1971): The Change to change; modernization, development and politics. Comparative Politics, 3, 3 .

HUTTON, W. (1995): The State We're in. New York: Vintage Press.

IMSERSO (1997): Teleasistencia domiciliaria. Evaluación del programa INSERSO/FEMP. Madrid.

INSERSO (1992b): Evaluación de la calidad de los servicios del Programa de Termalismo Social. Madrid.

INTRESS (1991): Público-Privado y Bienestar social. Barcelona.

KAPLAN, R.S. y NORTON, D.P. (1992): Evaluación de resultados: algo más que números. Harvard Deusto Business Review, 24.

KEARNS, P.S. (1996): Privatization of human services: problems with contracting out theory. JHHSA SUMMER, 61-78.

KOVAR, S. (1996): Droit communautaire et service public: esprit dorthodoxie ou pensée larcisée, RTDE, 2, abril-junio, págs. 215 a 258.

LACASTA, J.J. (1997): Calidad organizacional: el cambio en las organizaciones no gubernamentales. Siglo Cero, 29, 1, 5-13.

LAPARRA, M. (1989): Privatización y servicios sociales. El caso de Navarra. Revista de Trabajo Social, 115, 57-81. 
LE GRAND, J. y ROBINSON, R. (1984): Privatisation and the Welfare State. London. George Allen \& Unwin.

LEONARDIS, O. (1996): I welfare mix e lêreditá difficile del welfare state. Assistenza Sociale, 1, 35-50.

LÓPEZ, J. y GADEA, A. (1995): Gestión de la calidad en la Administración Pública. Madrid. Gestión 2000.

LÓPEZ RUPÉREZ, F. (1994): La gestión de la calidad en educación. Madrid. La Muralla.

LUQUE, O. (1988): Intervención psicosocial en servicios sociales. Valencia. Nau Llibres.

LYOSN, K; LA VALLE, I. y GRIMWOOD, C. (1995): Career patterns of Qualified Social Workers: Discussion of a Recent Survey. British Journal Social Work, 25, 173-190.

MACKESY, R. (1993): Physician satisfaction with Rural Hospitals. Hospital \& health Services Administration, 38, 3, 375-386.

MADERA, M.V.; JURADO, M. y DE MIGUEL, M. (1995): Evaluación del protocolo de acogida para la mejora del trato al usuario en un servicio de medicina interna. En XII Congreso de la Sociedad Española de Calidad Asistencial. Revista de Calidad Asistencial, 12.

MALDONADO, A. y MARCH, J,C. (1994): Diseño de un plan de acogida de usuarios. En IX Jornadas de Salud Pública y Administración Sanitaria, pág. 127. Granada. Escuela Andaluza de Salud Pública.

MANN, K. (1991): Privatización del Bienestar, individualismo y Estado. En G. Rodríguez Cabrero: Estado, privatización y bienestar. Pág. 95-129.

MARTIN, L.L. (1993): Total Quality Management: The new Managerail Wave. Administration in Social Work, 17, 2, 1-15

MARTÍN MATEO, R. (1994): Liberalización de la economía (más Estado menos Administración ). Madrid. Trivium.

MARTÍN SANTOS, J.A. (1995): Sobre la privatización en servicios sociales. Documentos de Trabajo Social, 5, 89-93.

MARTÍNEZ DEL OLMO, M.T. (1994): La calidad de los servicios sanitarios y la participación de los usuarios. En IX Jornadas de Salud Pública y Administración Sanitaria, pág. 81. Granada. Escuela Andaluza de Salud Pública.

MAS, Ll; DEULOFEU, F.; SABÉ, A.; PAGÉS, A.; COLL, M. y RIU, Ll. (1997): Encuesta de satisfacción de los usuarios del servicio de urgencias. En XV Congreso de la Sociedad Española de Calidad Asistencial. Revista de Calidad Asistencial, 12, 347.

MEDINA TORNERO, M.E. (1993b): Análisis de calidad en los centros residenciales para mayores. En La Cristalera, 2, 41-49. Murcia: CARM. Dirección General de Bienestar Social. 
MEDINA TORNERO, M.E (1994): Consideraciones criticas a la vigencia u futuro del Plan Concertado. En I Congreso Nacional sobre el Sistema Público de Servicios Sociales en la Administración Local. Ayuntamiento de La Coruña, pág. 75-86.

MEDINA TORNERO, M.E. (1995): Organizar, Planificar y evaluar en las entidades asociativas. Murcia. Federación de Asociaciones Murcianas de Discapacitados Físicos (FAMDIF).

MEDINA TORNERO, M.E. (1996a): Gestión de Servicios Sociales. Murcia. PPU/Diego Marín.

MEDINA TORNERO, M.E. (1996b): La evaluación, garantía de calidad para los programas de intervención social. Simposio de Evaluación en la Intervención Socioeducativa. Fundació Pere Tarrés, Barcelona, Universitat Ramón Llull (Educación Social, 5, 46-69).

MEDINA TORNERO, M.E. (1996c): Evaluación de la calidad asistencial en Servicios Sociales. Intervención Psicosocial, 5, 14, 23-42.

MEDINA TORNERO, M.E. (1997a): La evaluación, de la calidad de los servicios sociales. II Congreso de Psicología Profesional. Murcia. Colegio Oficial de Psicólogos.

MEDINA TORNERO, M. E. (1997b): Utilidad de la evaluación en los servicios sociales comunitarios. Apuntes de Psicología, 49-50, 127-151.

MEDINA TORNERO, M.E. (1998): Evaluación de la calidad asistencial del servicio de ayuda a domicilio del Ayuntamiento de Murcia (1996-1997). Tesis Doctoral. Universidad de Murcia.

MENDOZA, X. (1991): Algunas reflexiones acerca de la transición al mercado de los servicios sociales. En INTRESS: Público-privado y Bienestar Social. Pág. 109.

MESCHERIAKOFF, S. (1991): Droit des services publics. París. PUF.

MILLWARD, R. y PARKER, D. (1983): Public and Private Enterprise: Comparative Behaviour and Relative Efficiency. En R. Millward (ed.): Public Sector Economic. New York. Longman.

Ministerio de Administraciones Públicas (MAP) (1996): Gestión y evaluación de la calidad en los servicios públicos. Madrid. MAP.

Ministerio de Trabajo y Asuntos Sociales y FERNÁNDEZ, S.(1997): Guía de integración laboral para personas con discapacidad. Estándares de calidad. Madrid.

MIRA, A.; VALLS, A.; VELASCO, J. y SERRA, M. (1997): Importancia de la opinión de los pacientes en la toma de decisiones. En XV Congreso de la Sociedad Española de Calidad Asistencial. Revista de Calidad Asistencial, $12,297$. 
MOORE, S. y KELLY, M.J. (1996): Quality Now: Moving Human Services Organizations toward a Consumer Orientation to Service quality. Social Work, 41, 1, 33-40.

MOORE, M.H. (1998): Gestión estratégica y creación de valor en el sector público. Madrid. Paidos.

MOTA, J. (1998): La gran expropiación. Madrid. Temas de Hoy.

MUÑOZ, S. (1998): Servicio público y mercado. Madrid. Civitas.

NAVARRO, V. (1998): Neoliberalismo y Estado del bienestar. Barcelona. Ariel.

ORTEGA, L. (1994): El reto dogmático del principio de eficacia, Revista de Administración Pública, 133.

PALLARÉS, L. y GARCÍA, M.J. (1996). Guía práctica para la evaluación. de la calidad en la atención enfermera. Madrid. Olalla Ediciones.

PAREJO ALFONSO, L. (1989): La eficacia como principio jurídico de la actuación de la Administración Pública, Documentación Administrativa, 218-219.

Parlement Européen, Direction Générale des Etudes (1996): Document de travail. Entreprises publiques et services publiques économiques dans l'Union Européenne, Luxemburgo.

PASCUAL, L.; AGUAS, J.M.; ALFONSO, D.; GARCÍA, E.; SANZ, R. y MARTÍNEZ, R. (1994): Análisis de la accesibilidad telefónica a un Centro de Salud. En XII Congreso de la Sociedad Española de Calidad Asistencial. Revista de Calidad Asistencial, 3, 127.

PEIRÓ, J.M. y MEDINA, M.E. (1996): Aspectos psicosociales de la gestión de servicios sociales. En IV Jornadas de Intervención Social, tomo 2, pág. 1147-1 183. Madrid: INSERSO/Colegio Oficial de Psicólogos.

PIRIE, M. (1990): Privatization: theory, practice and choice. London. Adam Smith Institute.

PORCEL MUNDO, A. (1997): La calidad total en el Trabajo Social. Revista de Servicios Sociales y Política Social, 59, 71-81.

PRIETO, M.A.; LÓPEZ, L.A. y MARCH, J.C. (1994): Percepción de usuarios sobre la calidad de los servicios de atención primaria y atención especializada. En IX Jornadas de Salud Pública y Administración Sanitaria, pág. 193-194. Granada. Escuela Andaluza de Salud Pública.

PUPPO, S. (1996): Patronato e welfare mix. Assistenza Sociale, 1, 63-70.

RANCI, C. (1996): Pubblico e privato nella transizione italiana verso il welfare mix. Assistenza Sociale, 1, 5-62.

RIPOLL, R. (1998): Libre competencia y ayudas a las empresas públicas. Valencia. Fundación Bancaixa.

RODRÍGUEZ CABRERO, G. (comp.) (1991): Estado, privatización y bienestar. Madrid. Icaria. 
RODRÍGUEZ RODRÍGUEZ, P. (1996): Analisis de la calidad de los servicios de teleasistencia en España: un estudio del INSERSO. En Jornadas Internacionales: Teleasistencia y Nuevas Tecnologias (documento fotocopiado).

RUIPÉREZ CANTERA, I. (1998): Calidad en la asistencia a las personas mayores. Revista Española de Geriatría y Gerontología, 33, 2, 63-66.

SACANELL , E. (1996): Aportaciones de la gestión de calidad en los servicios sociales. IV Jornadas de Intervención Social. Tomo 2, pág. 12611270. Madrid. Colegio Oficial de Psicólogos de Madrid/INSERSO.

SACANELL, E. (1998): Evaluación y calidad de la intervención social en el curriculum docente. En II Congreso de Escuelas Universitarias de Trabajo Social, pág. 352-355. Madrid. Escuela Universitaria de Trabajo Social. Universidad Complutense.

SÁNCHEZ, M.; ORTIZ, A. y PINEDA, A.I. (1994): Teléfono de atención al paciente: un aumento de la calidad asistencial. En IX Jornadas de Salud Pública y Administración Sanitaria, pág. 130. Granada. Escuela Andaluza de Salud Pública.

SÁNCHEZ, J.A.; SATURNO, P.J. y PORSPER-S. (1997): Evaluación de la calidad desde la perspectiva del paciente. Validación de un cuestionario tipo informe del usuario. En XV Congreso de la Sociedad Española de Calidad Asistencial. Revista de Calidad Asistencial, 12, 289-290.

SEIT (1993): Evaluación de la calidad del indicador tratamiento del Sistema estatal de Información sobre Toxicomanías (SEIT). Revista de Sanidade Higiene Pública, 67, 385-399.

SERRA, A. (1991): La estructuración de la sociedad: el sector público y el sector privado. En INTRESS: Público-privado y Bienestar Social. Pág. 65-77.

SOLIMAN, H. y POULIN, J. ( 1997): Client Satisfaction with Crisis Outreach Services: The development of an Index. Journal of Social Service Research, 23, 2, 55-71.

STARR, P. (1995): The meaning of Privatization. Project on the Federal Social role. Working paper, 6, 231.

STORR, A. (1996): Total Quality Management: Organizational Transformation or passing Fancy?. Administration in Social Work, 20, 3, 75-94.

STOKER, R.; WILSON, L.; THOMAS, L. y CLARK, G. (1997): Paternalistic welfare reform: current perceptions and behavioral models. JHHSA SUMMER, 5, 62-82.

SUÁREZ, F.,CIFUENTES, R. y MERCHÁN, E. (1991): La calidad asistencial y los recursos humanos en las residencias de ancianos. Revista Española de Geriatría y Gerontología, 1 (suplemento). 
SUÑOL, R. (1987): El estudio de la opinión del usuario y su aplicación en los programas de control de calidad. Control de Calidad Asistencial, 2, 15-22.

TAYLOR-GOOBY. P. (1991): La privatización y el futuro del Estado de Bienestar británico. En G. Rodríguez Cabrero: Estado, privatización y bienestar. Barcelona. Icaria.

TORRES GÓMEZ, B. (1996): Principales razones y consecuencias del «burnout» en los profesionales de los servicios de bienestar social de la CAV: posibles vías de solución. Vitoria. Servicio Central de Publicaciones del Gobierno Vasco.

VILLANUEVA, S.; GARCÍA, M.; GOIKOETXEA, A.; CEREZO, M.; VALERO, M.A. y GUTIÉRREZ, G. (1997): Evaluación de tiempos de espera y satisfacción de pacientes en el servicio de urgencias de un hospital terciario. En XV Congreso de la Sociedad Española de Calidad Asistencial. Revista de Calidad Asistencial, 12, 349.

VILLAR ROJAS, F.J. (1993): Privatización de servicios públicos, la experiencia española a la luz del modelo británico. Madrid. Tecnos.

VUORI, H. (1988): El control de calidad en los servicios sanitarios. Madrid. Masson.

WARE, J. E. (1978): Effects of acquiescent response set on patient satisfaction ratings. Med. Care. 16, 327.

WILDING, P. (1994): Maintaining Quality in Human Services. Social Policy and Administration, 28, 1, 57-72.

YARROW, G. (1989): Privatization in Theory and Practice. Economic policy, 1. 